Louisiana State University

LSU Digital Commons

1996

\title{
A Case-Based Reasoning Approach to Bankruptcy Prediction Modeling.
}

Stephanie Mattox Bryant

Louisiana State University and Agricultural \& Mechanical College

Follow this and additional works at: https://digitalcommons.Isu.edu/gradschool_disstheses

\section{Recommended Citation}

Bryant, Stephanie Mattox, "A Case-Based Reasoning Approach to Bankruptcy Prediction Modeling." (1996). LSU Historical Dissertations and Theses. 6321.

https://digitalcommons.Isu.edu/gradschool_disstheses/6321

This Dissertation is brought to you for free and open access by the Graduate School at LSU Digital Commons. It has been accepted for inclusion in LSU Historical Dissertations and Theses by an authorized administrator of LSU Digital Commons. For more information, please contact gradetd@lsu.edu. 


\section{INFORMATION TO USERS}

This manuscript has been reproduced from the microfilm master. UMI films the text directly from the original or copy submitted. Thus, some thesis and dissertation copies are in typewriter face, while others may be from any type of computer printer.

The quality of this reproduction is dependent upon the quality of the copy submitted. Broken or indistinct print, colored or poor quality illustrations and photographs, print bleedthrough, substandard margins, and improper alignment can adversely affect reproduction.

In the unlikely event that the author did not send UMI a complete manuscript and there are missing pages, these will be noted. Also, if unauthorized copyright material had to be removed, a note will indicate the deletion.

Oversize materials (e.g., maps, drawings, charts) are reproduced by sectioning the original, beginning at the upper left-hand comer and continuing from left to right in equal sections with small overlaps. Each original is also photographed in one exposure and is included in reduced form at the back of the book.

Photographs included in the original manuscript have been reproduced xerographically in this copy. Higher quality $6 " \times 9 "$ black and white photographic prints are available for any photographs or illustrations appearing in this copy for an additional charge. Contact UMI directly to order.

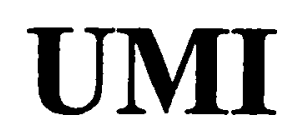

A Bell \& Howell Information Company 300 North Zeeb Road, Ann Arbor MI 48106-1346 USA $313 / 761-4700 \quad 800 / 521-0600$ 


\title{
A CASE-BASED REASONING APPROACH TO BANKRUPTCY PREDICTION MODELING
}

\author{
A Dissertation \\ Submitted to the Graduate Faculty of the \\ Louisiana State University and \\ Agricultural and Mechanical College \\ in partial fulfillment of the \\ requirements for the degree of \\ Doctor of Philosophy \\ in
}

The Department of Accounting

\author{
by \\ Stephanie M. Bryant \\ B.S., Louisiana State University, 1988 \\ December 1996
}


UMI Number: 9720335

\section{UMI Microform 9720335}

Copyright 1997, by UMI Company. All rights reserved.

This microform edition is protected against unauthorized copying under Title 17, United States Code.

\section{UMI \\ 300 North Zeeb Road \\ Ann Arbor, MI 48103}




\section{ACKNOWLEDGEMENTS}

My heartfelt thanks go to my committee members for their support: Professors Barbara Apostolou (chair); Andrew Christie; E. Barry Moser; Robert Mathews; and Thomas Lynch. Their insights and patience are greatly appreciated.

I would also like to thank my husband, Gary, and my daughters, Samantha and Amber. They are the wind beneath my wings. 


\section{TABLE OF CONTENTS}

ACKNOWLEDGEMENTS $\ldots \ldots \ldots \ldots \ldots \ldots \ldots \ldots \ldots \ldots$ ii

LIST OF TABLES $\ldots \ldots \ldots \ldots \ldots \ldots \ldots \ldots \ldots \ldots \ldots \ldots$

ABSTRACT $\ldots \ldots \ldots \ldots \ldots \ldots \ldots \ldots \ldots \ldots \ldots \ldots \ldots \ldots \ldots \ldots \ldots \ldots \ldots$

\section{CHAPTER}

1. OVERVIEW OF THE STUDY $\ldots \ldots \ldots \ldots \ldots \ldots \ldots \ldots \ldots$

Case-Based Reasoning (CBR) $\ldots \ldots \ldots \ldots \ldots \ldots \ldots \ldots 2$

Bankruptcy Prediction Modeling $\ldots \ldots \ldots \ldots \ldots \ldots \ldots$

Research Objectives ..................... 6

Research Method .................... 7

Expected Contribution ................... 8

Summary $\ldots \ldots \ldots \ldots \ldots \ldots \ldots \ldots \ldots \ldots, 9$

2. REVIEW OF THE LITERATURE $\ldots \ldots \ldots \ldots \ldots \ldots \ldots \ldots 11$

CBR Literature ...................... 11

Bankruptcy Modeling Literature .............. 21

Summary ........................ 29

3. RESEARCH METHOD $\ldots \ldots \ldots \ldots \ldots \ldots \ldots \ldots \ldots \ldots \ldots$

Research Objectives $\ldots \ldots \ldots \ldots \ldots \ldots \ldots \ldots \ldots, 34$

Hypotheses . ..................... 35

Phase I: Design and Construction of the CBR System ..... 36

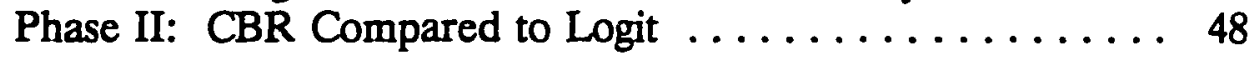

Sample Selection and Data Collection ............ 50

Statistical Tests ...................... 52

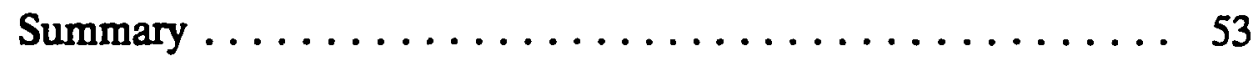

4. RESULTS $\ldots \ldots \ldots \ldots \ldots \ldots \ldots \ldots \ldots \ldots \ldots \ldots \ldots \ldots \ldots \ldots$

Sample Selection Procedures $\ldots \ldots \ldots \ldots \ldots \ldots \ldots .54$

Descriptive Statistics $\ldots \ldots \ldots \ldots \ldots \ldots \ldots \ldots \ldots . \ldots \ldots$

CBR Analysis $\ldots \ldots \ldots \ldots \ldots \ldots \ldots \ldots \ldots \ldots \ldots \ldots \ldots \ldots \ldots \ldots$

Holdout Samples ...................... 63

Tests of Hypothesis One $\ldots \ldots \ldots \ldots \ldots \ldots \ldots \ldots \ldots 65$

iii 
Tests of Hypothesis Two: Logit Analysis . . . . . . . 71

Additional Analysis ..................... 83

Summary $\ldots \ldots \ldots \ldots \ldots \ldots \ldots \ldots \ldots \ldots \ldots, 85$

5. SUMMARY AND CONCLUSIONS $\ldots \ldots \ldots \ldots \ldots \ldots \ldots, 86$

Summary of Study and Implications $\ldots \ldots \ldots \ldots \ldots \ldots 86$

Limitations ........................ 93

Suggestions for Future Research $\ldots \ldots \ldots \ldots \ldots \ldots .96$

REFERENCES $\ldots \ldots \ldots \ldots \ldots \ldots \ldots \ldots \ldots \ldots \ldots \ldots \ldots \ldots$

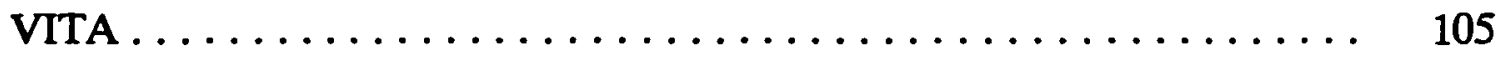




\section{LIST OF TABLES}

\section{TABLE}

1. A Chronological Summary of Relevant Bankruptcy Modeling Studies 30

2. Results of Ohlson's (1980) Type I and Type II Error Rates, Model One, One Year Prior to Bankruptcy ............. 32

3. Results of Ohlson's (1980) Type I and Type II Error Rates, Model Two, Two Years Prior to Bankruptcy ............. 33

4. Case Attributes $\ldots \ldots \ldots \ldots \ldots \ldots \ldots \ldots \ldots \ldots \ldots \ldots \ldots \ldots$

5. Description of Ohlson (1980) Variables $\ldots \ldots \ldots \ldots \ldots \ldots \ldots 49$

6. Sample Selection of Bankrupt Firms ............... 55

7. Distribution of Years of Bankruptcy Filing for 85 Bankrupt Firms ... 57

8. Descriptive Statistics CBR and Logit Variables ............ 59

9. Verification of the CBR Completeness, Distribution of Missing Attributes Across CBR Cases .................. 62

10. Verification of the CBR Completeness, Distribution of Nil Slots per CBR Attribute $\ldots \ldots \ldots \ldots \ldots \ldots \ldots \ldots \ldots, 64$

11. Holdout Samples $\ldots \ldots \ldots \ldots \ldots \ldots \ldots \ldots \ldots \ldots \ldots \ldots \ldots$

12. Results of CBR Cluster Tree Analysis: Model One, Holdout Sample of 157 Firms from 1975-1989, Averaged Over V=10 Separate Views ..........................6 67

13. Results of CBR Cluster Tree Analysis: Model Two, Holdout Sample of 157 Firms from 1975-1989, Averaged Over V=10 Separate Views $\ldots \ldots \ldots \ldots \ldots \ldots \ldots \ldots \ldots \ldots \ldots, 68$ 
14. Results of CBR Cluster Tree Analysis: Model Three, Holdout Sample of 157 Firms from 1975-1989, Averaged Over V=10 Separate Views ..................... 69

15. Results of CBR Cluster Tree Analysis: Model One, Holdout Sample of 514 Firms from 1990-1994, Averaged Over V=10 Separate

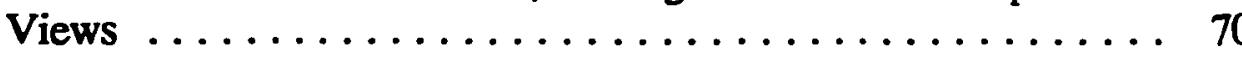

16. Results of CBR Cluster Tree Analysis: Model Two, Holdout Sample of 514 Firms from 1990-1994, Averaged Over V=10 Separate

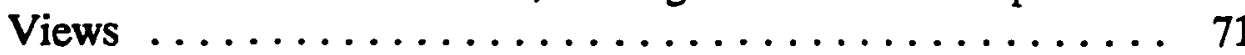

17. Results of CBR Cluster Tree Analysis: Model Three, Holdout Sample of 514 Firms from 1990-1994, Averaged Over V=10 Separate Views ...................... 72

18. Parameter Estimates for Logit Model One ............. 74

19. Parameter Estimates for Logit Model Two ............. 75

20. Parameter Estimates for Logit Model Three ............ 75

21. Logit Model One: Analysis of Cutoff Points, Holdout Sample of 148 Firms from 1976-1989 .................... 77

22. Logit Model Two: Analysis of Cutoff Points, Holdout Sample of 148 Firms from $1976-1989 \ldots \ldots \ldots \ldots \ldots \ldots \ldots \ldots$

23. Logit Model Three: Analysis of Cutoff Points, Holdout Sample of 148 Firms from $1976-1989$. . . . . . . . . . . . . . . 79

24. Logit Model One: Analysis of Cutoff Points, Holdout Sample of 514 Firms from $1990-1994 \ldots \ldots \ldots \ldots \ldots \ldots \ldots \ldots \ldots$. 80

25. Logit Model Two: Analysis of Cutoff Points, Holdout Sample of 514 Firms from 1990-1994 ..................... 81

26. Logit Model Three: Analysis of Cutoff Points, Holdout Sample of 514 Firms from $1990-1994 \ldots \ldots \ldots \ldots \ldots \ldots \ldots \ldots . \ldots 2$

27. Comparison of Type I and Type II Errors Rates Between CBR Model and Logit Model ................... 84 


\begin{abstract}
This study examines the usefulness of an artificial intelligence method, casebased reasoning (CBR), in predicting corporate bankruptcy. Based on prior research, $C B R$ is believed to be a viable method of predicting bankruptcy. Hypotheses are developed to test the usefulness of a CBR system and to compare the accuracy of such a system to the model considered to be the benchmark model in bankruptcy prediction, Ohlson's (1980) nine-factor logistic regression (logit) model.
\end{abstract}

Sample data consisting of manufacturing and industrial firms is drawn from the Compustat database in a 20:1 ratio of nonbankrupt to bankrupt firms, consistent with Ohlson's (1980) proportions. Three CBR models representing one, two, and. three years before bankruptcy are designed and developed using a CBR development tool, ReMind. Cross-validation is done using a $10 \%$ in-period holdout sample as well as a holdout sample of firms from outside the period from which the model is constructed. Three logit models based on Ohlson (1980) representing one, two, and three years before bankruptcy are constructed. The usefulness of the CBR system is determined by examination of type I and type II error rates. Chi-square statistics are used to compare the predictive accuracy of the three CBR models with the three logit models.

vii 
The results indicate that the CBR method using ReMind is not useful in predicting corporate bankruptcy. It is believed that the small sample of bankrupt firms (relative to the sample size of nonbankrupt firms) contributes to the failure of these CBR models to accurately predict bankruptcy. Compared with two other studies that also use ReMind as development tools, there is evidence that the algorithm in ReMind does not accommodate small sample sizes. The results also indicate that CBR is not more accurate than the Ohlson (1980) logit model. Ohlson's (1980) logit models attain a much higher accuracy rate than the CBR models and appear to be more stable over time than the CBR models. 


\section{CHAPTER 1}

\section{OVERVIEW OF THE STUDY}

The continuing search for a more accurate bankruptcy method is evident from an examination of the research in this area. ${ }^{1}$ One reason for the continued interest undoubtedly is due to the great number of stakeholders in a given company's viability. Stockholders care about whether their investments are safe. Lenders have a vital interest in accurately assessing the risk of default for potential loans. Auditors are required by generally accepted auditing standards to assess whether a client company is in danger of not continuing for 12 months beyond the balance sheet date. Employees and managers care about their future employment and their own investment in company stock. Thus, the search for methods that can. improve the predictive accuracy of existing statistical models continues.

Bankruptcy prediction modeling has progressed from univariate analysis to multivariate techniques such as discriminant analysis and, most recently, to artificial

'The terms failure, insolvency, and bankruptcy often are used interchangeably. Altman (1983, 5-7) distinguishes the terms as follows: In an economic sense, failure means that the realized rate of return on invested capital, with allowances for risk considerations, is significantly and continually lower than prevailing rates on similar investments. Thus, a company may be an economic failure for many years. Insolvency exists when a firm cannot meet its current obligations. Bankruptcy occurs when a company files a formal legal document in federal district court for the purpose of either liquidation or reorganization. 
intelligence (AI) methods such as neural networks. ${ }^{2}$ Although there has been substantial research directed at developing a neural network that could outperform the predictive accuracy of existing statistical models, the results have been mixed. Recently, however, advances in artificial intelligence have led to a new AI technique known as case-based reasoning (CBR) that provides a desirable alternative to a neural network. The primary purpose of this study is to design, develop, and test a CBR bankruptcy prediction system.

\section{Case-Based Reasoning (CBR)}

\section{CBR as a Model of Dynamic Memory}

CBR is an artificial intelligence system and technology gaining widespread acceptance. Schank (1982) provides the foundation for the work in CBR in Dynamic Memory. This work is the first to describe a memory-based approach to reasoning and to give an architecture for building that type of reasoning system on a computer (Barletta 1991, 3). The basic principle underlying CBR is that human experts use analogical or experiential reasoning to solve complex problems and to learn from problem-solving experiences (Brown and Gupta 1994, 205). However, in searching their memories, human experts may suffer from primacy (remembering the first thing more vividly) and/or recency (remembering the last thing more vividly) effects (Brown and Gupta 1994, 205). CBR allows for a systematic search

${ }^{2}$ Artificial intelligence refers to a computer system that performs tasks normally associated with human intellectual capacity (Summers 1991, 659). It includes work in natural languages, robotics, expert systems, neural networks, and case-based reasoning. 
of a case library (memory) in order to retrieve cases that most closely match the problem at hand. $A$ CBR system can augment an expert's memory by retrieving a larger and more relevant set of cases than human memory can retrieve (Kolodner 1993).

CBR has been shown to accurately model human decision-making processes. For example, Morris $(1992,1994)$ develops a CBR system that evaluates EDP controls and generates information system control recommendations. Morris (1994, 49) notes that auditors use past cases to compare controls, to remind them of previous incidences where controls failed, to generate expectations about client controls and to justify or explain their control recommendations. Morris validates her system by comparing its performance against human subjects. The CBR system outperforms the human subjects in generating control recommendations. Further evidence that CBR accurately models human decision-making processes is provided by Biggs, Messier, and Hansen (1987) and Meservy, Bailey, and Johnson (1986), who both note that auditors reason by analogy to prior experiences. Brown and Gupta $(1994,205)$ claim that the ability of CBR to augment human memory and facilitate machine learning is a significant contribution to the study of intelligent systems.

\section{Why is CBR Better?}

CBR models are faster, easier, and less expensive to design and implement than rule-based expert systems, neural networks, and pattern-recognition techniques 
such as discriminant analysis (Barletta 1991). ${ }^{3}$ Updating a CBR system is easier than updating expert systems and neural networks because it only requires adding a new case to the system. Updating an expert system can require many hours of intricate re-adjustment of the rule base. Neural networks may have to be re-trained. For complex networks, this process may require weeks of CPU time to train a single network (Barletta 1991, 47). Additionally, expert systems, neural networks and statistical models provide virtually no explanation for their resultant classifications. CBR models provide a rich set of cases as an explanation for a classification decision. The user can compare the current case with cases the CBR model retrieves to see exactly why the CBR classified a case a particular way.

Predictive accuracy of a CBR system is of chief importance. Several prominent papers compare neural networks, pattern recognition, and symbolic induction. ${ }^{4}$ For example, Weiss and Kapouleas (1989) compare two inductivelearning techniques with two neural-network approaches and four patternrecognition approaches on five real data sets. Barletta $(1991,48)$ reports that inductive techniques were slightly more accurate than neural networks and were much more accurate than pattern-recognition approaches. This finding suggests that a CBR model could be more accurate than both a neural network and logistic regression and motivates the current study.

\footnotetext{
${ }^{3}$ Pattern recognition refers to mathematical functions such as linear or quadratic discriminant analysis and Bayes (probabilistic) classifiers such as logistic regression.

${ }^{4}$ Symbolic induction refers to machine learning algorithms commonly used in CBR and sometimes used in neural networks.
} 
Research in neural networks shows that a critical area in design of the network is selection of predictor variables. Boritz and Kennedy $(1995,17)$ state:

We demonstrate that the performance of the neural networks is sensitive to the choice of variables selected and that the networks cannot be relied upon to "sift through" variables and focus on the most important variables. . .

Since CBR inductively builds the decision tree, it has the capability of inducing the weights of the predictor variables by examination of the data. This capability is a substantial advantage over neural networks.

\section{Bankruptcy Prediction Modeling}

There have been sporadic attempts at theory development in bankruptcy prediction. Jones (1987) notes the absence of theory, and observes that predictive models can be developed based on existing historical information, i.e., cases. Due to the lack of a theory of bankruptcy, research in bankruptcy modeling has been driven by the attempt to develop classification techniques that aid in discriminating between companies that are likely to go bankrupt and those that are not likely to go bankrupt. The emphasis has been on discovering which variables have the greatest explanatory power and which methods are the most accurate. The current study blends these two interests by drawing on microeconomic variables that have proven valuable in the classification task in previous research, and then using these variables to develop a CBR model. The second chapter provides a comprehensive literature review of both the CBR literature and bankruptcy modeling literature.

${ }^{5}$ Wilcox (1971) attempts to develop a simple theory of financial ratios as predictors of failure by using a gambler's ruin model. 


\section{$\underline{\text { Research Objectives }}$}

The primary purpose of this study is to design, develop, and test a CBR bankruptcy prediction system. Two research questions are raised to address these issues:

1. Can a CBR system be used to predict bankruptcy?

2. Is the predictive accuracy of a CBR system greater than Ohlson's (1980) nine-factor model of bankruptcy prediction?

The first question deals with the usefulness of a CBR bankruptcy prediction system. The CBR system is judged to be useful if its predictive accuracy is better than the expected accuracy attained by chance. The second question of interest is whether this system provides a more accurate model for predicting bankruptcy than existing statistical models. Accordingly, this study compares the predictive accuracy of a CBR model with that of Ohlson's (1980) nine-factor model, which has been found to be the most accurate statistical model currently in use. ${ }^{6}$ Hypotheses are derived to test these two research questions. Data sufficient to test the hypotheses is drawn from the Compustat (Standard and Poor) database for the 20-year period 1975-1994.

\footnotetext{
${ }^{6}$ Begley, Ming, and Watts (1995) examine the stability and predictive accuracy of both Altman's (1968) discriminant analysis model and Ohlson's (1980) logistic regression (logit) model. They find that Ohlson's (1980) model results in less type I and type II errors than Altman's (1968) model when applied to data from the 1980s. They further find that Ohlson's (1980) model re-estimated with 1980s data is more accurate than Altman's (1968) model re-estimated with 1980s data. The second chapter provides a detailed discussion of the research of Begley, Ming, and Watts (1995).
} 
The third chapter provides a detailed discussion of the hypotheses and the sampling procedures.

\section{Research Method}

The current study uses CBR to design and construct a bankruptcy prediction system. A CBR case library is built consisting of financial ratios gathered on a random sample of bankrupt and nonbankrupt firms. To enhance comparability of the predictive accuracy of CBR with Ohlson's (1980) logit model of bankruptcy prediction, an effort is made to closely follow Ohlson's (1980) sampling procedures. Accordingly, the proportion of bankrupt to nonbankrupt firms is $1: 20$, and only manufacturing and industrial firms are used. A random sample consisting of 85 bankrupt and 2,000 nonbankrupt manufacturing and industrial firms from the period 1975-1994 is generated from the Compustat database. ${ }^{7}$ For the bankrupt firms, three years of data is gathered, with year one being one year before bankruptcy; year two, two years before bankruptcy; and year three, three years before bankruptcy. One hundred nonbankrupt firms for each year 1975-1994 are randomly selected. Data for the nonbankrupt firms consists of a single vector of data points per firm. For each firm, 25 financial ratios found significant in the literature are calculated and comprise the case attributes in the CBR system. Following Ohlson (1980), three CBR models are generated: model one predicts bankruptcy within

\footnotetext{
${ }^{7}$ Bankrupt firms were selected using Compustat's 1994 Annual PrimarySupplementary-Tertiary Industrial Research Files and 1994 Over-the-Counter Research File. Nonbankrupt firms were selected using the 1994 Annual Industrial PrimarySupplementary-Tertiary File and the 1994 Annual Over-the-Counter File. Compustat's Full-Coverage File was not used due to local unavailability.
} 
one year; model two predicts bankruptcy within two years given that the company did not fail within the subsequent year; and model three predicts bankruptcy within one or two years. ${ }^{8}$ Three CBR models are derived using data from 1975-1989. The remaining data is used to cross-validate the three models. The CBR system employs inductive indexing to generate a cluster decision tree with the minimum number of nodes needed to provide a classification decision. This decision tree is then used to classify a hypothetical case as bankrupt or not bankrupt. The usefulness of CBR is assessed by examination of prediction error rates for nonbankrupt and bankrupt firms. The study also compares the predictive accuracy of the CBR with the predictive accuracy of Ohlson's (1980) nine-factor logit model. A chi-square test is performed to compare the two methods.

\section{Expected Contribution}

Because there is a lack of economic theory regarding why companies go bankrupt, bankruptcy prediction modeling to date has focused on developing the most accurate models possible. This emphasis has involved testing various methods

\footnotetext{
${ }^{8}$ Studies have developed bankruptcy prediction models for anywhere between one and five years before bankruptcy. Ohlson (1980) describes three models of bankruptcy prediction: one year before bankruptcy, two years before bankruptcy, and three years before bankruptcy. Altman (1968) develops discriminant analysis models as far back as five years before bankruptcy. However, predictive accuracy diminishes substantially as the lead time increases (Altman 1968, 604). Altman (1968) reports accuracy rates of $95 \%, 72 \%, 48 \%, 29 \%$, and $36 \%$ for years one through five before bankruptcy, respectively. Beaver's (1968) univariate analysis of financial ratios finds that predictive accuracy diminishes after year two. The ratio with the highest predictive accuracy, cash flow to total debt, has accuracy rates of $87 \%, 79 \%, 77 \%, 76 \%$, and $78 \%$ for years one through five before bankruptcy, respectively. To enhance comparability of Ohlson's (1980) models with the CBR models, the current research develops three models.
} 
and attempting to identify the most discriminatory independent variables. Although Altman (1968) and Ohlson (1980) both claim high accuracy rates, Begley, Ming, and Watts (1995) demonstrate the decline in predictive accuracy when the models are tested with data from outside the years from which the models are created. The study adds to the bankruptcy literature in determining the predictive accuracy of a CBR system as compared to Ohlson's (1980) logit model of bankruptcy prediction.

This study is also the first to demonstrate design and construction of a bankruptcy prediction CBR system. Brown and Gupta $(1994,220)$ state:

Few CBR systems have been developed to date in the accounting domain. Thus, showing that systems can be effectively developed for a variety of accounting tasks is a viable research area.

This study addresses this call for a demonstration of development of an effective accounting application in the CBR arena.

\section{Summary}

This chapter presents an overview of the current study. The two research objectives are stated and discussed. CBR is introduced as a model of dynamic memory and reasons why CBR can be expected to provide better results than existing statistical models are stated.

This study offers great theoretical and practical significance. Theoretically, this is the first attempt to demonstrate a model of bankruptcy prediction using CBR and contributes to that literature. Practically, depending upon the results, the resultant CBR system may prove to be extremely useful in the everyday world to 
lenders, auditors, stockholders, and others interested in a given company's financial future. 


\section{CHAPTER 2}

\section{REVIEW OF THE LITERATURE}

There are two distinct areas of literature relevant to the current study. Examination of the case-based reasoning (CBR) literature reveals the stream of research in CBR, including the advent of $C B R$, applications of $C B R$ to the accounting domain, and advances in verification and validation of CBR systems. The bankruptcy literature reveals developments in bankruptcy modeling techniques, from univariate models to discriminant analysis models to logit models to neural networks. This chapter discusses the CBR literature first, the bankruptcy modeling literature next, and concludes with a summary of the chapter.

\section{CBR Literature}

CBR originates in Schank's (1982) book Dynamic Memory, in which he discusses his theories of adaptable memory structures, i.e. "dynamic memory." In trying to identify why people are reminded of an old experience by a new one, Schank (1982) develops a theory of high level memory structures that he applies to both humans and computers. He theorizes that humans store information by abstracting significant generalizations from experiences and storing the exceptions to those generalizations. A dynamic memory, then, is one that learns through 
adjusting a current memory on the basis of a failed expectation created by a high level memory structure.

Schank (1982) also argues that this process of reminding is not a chance happening, but rather that humans are constantly receiving new inputs and evaluating and understanding them in terms of previously processed inputs (Schank 1982, 22). Experts, in particular, because of their status as experts and command of domain-specific information, are reminded in greater detail and more frequently than nonexperts. ${ }^{9}$ He discusses development of an expert system and the knowledge acquisition necessary to accomplish this goal. Schank (1982) identifies two possible avenues to extract the knowledge necessary for such a system. The first option is to get the compiled knowledge of the expert; that is, identify the specific rules that an expert utilizes in arriving at a decision. Schank (1982) points out that even if this rule acquisition were completely successful, a significant drawback would be that such a system would not be able to reorganize what it knew (i.e., would not be able to learn).

Schank (1982) then sets forth his alternative to model the raw memory of the expert. It is this model that is the basis for CBR. Schank describes the model (Schank 1982, 22):

This (attempt to model the raw memory of the expert) would involve creating a set of categories of subdomains of the expertise in question and equipping the system with rules for the automatic modification

${ }^{9}$ An expert is anyone with superior knowledge in a given domain. Schank (1982, 22) acknowledges that in a sense, we are all experts, as we are experts on our own experiences. 
of those categories. Such a system would attempt to process new experiences in terms of the most closely related old experiences available. Upon finding an episode that strongly related, whatever that might turn out to mean, a reminding would occur. The new episode would then be indexed in terms of the old episode. New categories would be built as needed when old categories turned out to be useless from either under-utilization or over-utilization, or because the expectations contained within them were too often wrong.

CBR as it is known today involves making a current decision by being reminded of the most similar case in memory and then adding the new case to memory for use in future decision-making tasks.

Although CBR systems have been developed in areas such as help desk application, medicine, law, negotiation planning, workers' compensation law, political dispute mediation, and military strategic planning, this research project focuses on CBR uses in business domains, and specifically in accounting. ${ }^{10}$ This section describes CBR systems in accounting. The review is structured along functional areas of accounting in the following order: financial accounting,

${ }^{10} \mathrm{Help}$ desk applications are the most successful application of CBR to date (Brown and Gupta 1994, 208). Other applications include JUDGE (Bain 1986a,b), for sentencing convicted criminals; HYPO (Ashley 1987, 1991; Ashley and Rissland 1988), for analyzing trade secrets; PERSUADER (Sycara 1988, 1990), for negotiation planning; MEDLATOR (Kolodner and Simpson 1989) for political dispute mediation; LAWCLERK (Selfridge and Cuthill 1989), for cross context reminding; GREBE (Branting 1989) for workers' compensation law; and TR2S (Huang 1990), for trademark infringement (Brown and Gupta 1994, 207-208). Additional systems include Protos (Bareiss 1989; Bareiss, Porter, and Weir 1988), a CBR system that classifies hearing disorders, and The Battle Planner (Goodman 1989), a CBR system built from an existing database of over 600 historical battles, that evaluates and suggests alternative courses of action in battle (Kolodner 1993, 587-588). A comprehensive review of known CBR systems is provided by Kolodner (1993, 581628). 
cost/managerial accounting, auditing (including internal auditing), and tax and legal issues of accounting. The CBR literature review section concludes with a discussion of CBR design and validation issues.

\section{Financial Accounting}

Buta (1994) describes an application of CBR to predict corporate bond rating. In this study, two years (1991-1992) of data and ratings information for 1,000 companies in the Compustat database are used to construct a prototype CBR that predicts the rating for a hypothetical company's bond. The CBR shell, ReMind (Cognitive Systems, 1992), is used for this task. ${ }^{11}$ Cases are represented as financial ratios for the companies. The case library consists of a total of 1,039 cases that had complete financial data available. Ten percent of the cases in the case library are randomly set aside for testing the system. ReMind's inductive machinelearning algorithm (discussed in Chapter 3) uses the remaining $90 \%$ of the cases to generate a binary decision tree. The resultant system classifies the $10 \%$ holdout sample correct $90.4 \%$ of the time. A second library is constructed with the original 1,039 cases and an additional 1,104 cases that were missing some data (and therefore missing some financial ratios). The decision tree created from this case library classifies bond ratings correctly $84.4 \%$ of the time. This research

${ }^{11} \mathrm{~A}$ CBR shell is a development tool that aids in creation of a CBR. It contains the inference engine, the machine learning algorithms to perform indexing and retrieval of cases, and a user interface that makes interaction with the system easy for users. Use of a CBR shell allows the user to concentrate on development issues such as knowledge representation and quality issues such as density of cases. The CBR shell, ReMind, was developed by Cognitive Systems, Inc. (Stamford, Connecticut), a company founded by Roger Schank. 
demonstrates the usefulness of CBR in mining financial databases, and development of a CBR system that can successfully predict corporate bond rating a high percentage of the time.

\section{Cost/Managerial Accounting}

Stottler (1994) creates a CBR for use in the retail industry. The goal of this CBR is to predict sales volume for a national retail chain for each store for each day of the week two weeks in advance. This information allows management to then schedule the most efficient number of workers on a given day. The company initially considered building an expert system or a neural network to perform this task. Management considered the expert system to be too complex to model the rulebase required and too much effort to construct. The neural network was discarded as too hard for managers to understand and insufficient in justification of final recommendations. $\mathrm{CBR}$ was chosen as an relatively easy system to build and use. A CBR pilot study using three years of daily sales data for 27 stores achieves an $8 \%$ variability in prediction of sales. Due to the success of the CBR pilot system, an additional 25 stores are currently testing the system, with plans to make the system available nationwide (Stottler 1994, 27).

Stottler (1994) discusses an implementation of CBR by an architectural/ engineering firm to estimate the cost of designing buildings so that an appropriate bid could be submitted. This system is prototyped using the CBR shell, Esteem (Esteem Software, Inc., Cambridge City, Indiana). Cases are represented as 20 years of the prior projects the firm had bid on and their final costs, along with 
attributes such as square footage, and number of stories. Although specific error rates for the system are not detailed, the system is described as being a successful application of CBR development methodology.

Mukhopadhyay, Vicinanza, and Prietula (1992) examine the feasibility of a CBR model for software effort estimation. A CBR system, Estor, is developed that estimates the number of worker-months necessary to develop a software application. Using data from a previous software development project, 10 projects are entered into the case library. Each project is comprised of 37 project factors as well as the final actual development effort associated with each project. The study compares both the accuracy and consistency of the CBR in predicting the number of workermonths necessary to develop a software application with the predictions of an expert in the field, and with two mathematical models, COCOMO and function point estimates. Consistent with their expectations, the expert is found to be the most accurate, with the CBR more accurate than the mathematical models. Accuracy is measured by performing a Page test on ordered alternatives. Consistency is measured by the correlation between actual effort and estimated effort for the sample projects. Mukhopadhyay, Vicinanza, and Prietula (1992) conclude that there is no significant difference in the consistency of the expert and Estor or two mathematical methods. However, the expert and Estor are found to be more consistent than the mathematical models. 


\section{Auditing}

Denna, Hansen, Meservy, and Wood (1992) provide an application of CBR to an auditing task. The goal of their CBR system is to model a specific audit judgment task, assessing the likelihood of a material error (LME) in a retail grocery store's financial statements. This system, entitled APE-II, is adapted from Bain's (1986a) Micro-Judge to model a single auditor's assessment of the LME related to net income. ${ }^{12,13}$ Cases in the library consist of typical retail grocery operations with attributes such as change in inventory, a series of operating events such as ordering inventory, receiving inventory, abnormal operating events such as trucker strike and employee strike, and risk level (e.g., high, moderate, low). The system predicts the direction of change in net income and the degree of change in net income, and the LME judgment of higher, lower, or the same as the standard expectations. APE-II is tested by using two test cases, one in which there is a trucker's strike and one in which there is an employee strike. In the first case, $A P E-I I$ determines that net income would likely decrease substantially, thereby causing a similar change in the LME relating to the inventory cases (Denna et al. 170). APE-II determines in the second case that the employee strike would cause a marginal decrease in net income and LME would be somewhat higher (Denna $e t$

${ }^{12}$ This work is an extension of earlier work by Denna (1989), which developed a model of auditor reasoning named Audit Planning and Evaluation (APE) (Denna et al. 1992, 168).

${ }^{13}$ Micro-Judge is a model of the experiences of two members of the Connecticut Superior Court. The CBR is created using code from Micro-Judge. 
al. 170). Although preliminary in nature, this research is important because it provides a more complete model of expert auditor reasoning involving prior experience than previously developed rule-based models.

Morris (1994) develops a CBR system, SCAN, that evaluates electronic data processing (EDP) controls and generates information system control recommendations as part of internal control evaluation. SCAN uses past cases to remind the user of previous control failures, to set expectations about case features and control, to use as a pattern against which to compare a client's controls and to help justify or explain its recommendations (Morris 1994, 47). SCAN uses a similarity rank to find and extract the most similar cases in the case library. Validation includes comparing the information system recommendation from the CBR with that of a "textbook model" set of recommendations and with a graduate student designed to represent a novice internal auditor. The objective is to determine whether inexperienced auditors' performance could be improved through the use of a CBR system. The CBR-generated recommendations are judged by an experienced information systems manager to be superior to the student's recommendations. The student's recommendations are judged to be superior to the textbook recommendations. Thus, Morris (1994) concludes that a novice internal auditor could benefit by using the CBR-generated information system recommendations in internal audit procedures. 


\section{Tax and Legal Applications of CBR}

TAX-HYPO (Ashley 1987; Ashley and Rissland 1988) is a system that operates in the domain of tax law. It is derived from an earlier CBR system, HYPO (Ashley 1987; Ashley and Rissland 1988). It operates in the CABARET environment, a domain-independent shell that integrates rule-based and case-based reasoning. Past tax cases are used to make determinations on current tax cases, especially with respect to the meaning of terms in the tax code and in the tax regulations. This research is important because it demonstrates an early application of $\mathrm{CBR}$ to the accounting domain.

Rissland and Skalak (1991) examine an application of CBR to the home office deduction domain under Section 280A of the Internal Revenue Code. Using the hybrid architecture of the CABARET environment, Rissland and Skalak (1991) create a case knowledge base consisting of 23 actually litigated tax cases and six hypothetical cases. The research illustrates how the system works for one actual case by describing the individual tasks the system performs in arriving at a final decision. Rissland and Skalak (1991) conclude by providing a summary of the strengths and weaknesses of CABARET. This research is particularly interesting as it provides a mixed paradigm system that includes a dynamic interleaving of rule based systems and case-based systems.

Van Zeeland (1993) describes a database mining application of CBR in the Netherlands. In this system, CBR is used to classify tax returns into one of four audit categories: Class 1, perform a complete field investigation; Class 2, perform 
a partial field investigation; Class 3 , perform an internal tax return investigation; and Class 4, perform no investigation of the tax return. The CBR shell ReMind is used to construct the CBR. Cases are represented as companys' historical tax returns, each with approximately 75 attributes (numerical values from the tax returns). There are a total of 300 cases in the case library, with 244 cases used to construct the cluster tree, and the remaining 27 cases used to test the tree. The study finds the highest classification rate is $57 \%$. Van Zeeland (1993) speculates that a more complete domain-model is needed to lead to a higher percentage of recognitions.

\section{CBR Design and Validation Considerations}

Although guidance regarding CBR design and validation is scarce in the literature, there are two notable papers that provide guidance in this area. O'Leary $(1993,57)$ discusses verification and validation of case-based systems and distinguishes them as follows:

Verification tests are aimed at "building the system right," and validation tests are aimed at "building the right system." Thus, verification examines issues such as ensuring that the knowledge in the system is represented correctly, while validation examines procedures to ensure the system makes correct decisions.

Verification issues include evaluating the consistency, completeness, correctness, and redundancy of the system. Consistency is discussed as a goal of parallel structures. This means verifying that each child node in a network has only one parent. A CBR system should also be complete in that all chosen cases are input accurately and completely in the case library. Correctness involves verifying the accuracy of 
the system against a benchmark. Redundancy is having the same case mistakenly entered twice into the case library or having two cases in the library with identical case attributes. The paper presents statistical and nonstatistical methods for each of these verification issues. Calculation of correlation coefficients between cases to examine similarity of attributes is one option suggested by O'Leary (1993). Other options are to determine the distribution of null values across cases for each attribute and to calculate the percentage of attributes missing for each case. Each of these calculations provide a guide as to the completeness of a given case library. Validation consists of ensuring the ex post quality of the CBR system. The question here is how accurate the resultant CBR system is compared with a benchmark decision model. O'Leary (1993) suggests mathematical programming (goal programming and generalized linear programming) and regression for use in comparative analysis. O'Leary (1993) also proposes that generic algorithms can be used to generate test cases. O'Leary's (1993) research is important because it represents an early attempt to isolate verification and validation techniques for use in CBR.

\section{Bankruptcy Modeling Literature}

Table 1 provides a summary of relevant bankruptcy modeling research. Bankruptcy modeling studies originated with univariate analysis and progressed to discriminate analysis, conditional probability models such as logit, and AI techniques such as neural networks. This section of the literature review discusses the significant studies and the methods each study employed. The studies included here 
are intended to be a representative sampling of studies that use each of the methods. ${ }^{14}$ The section concludes with a summary of this chapter.

\section{Beaver (1966)}

The stream of research in modeling techniques begins with Beaver's (1966) univariate analysis in which he identifies 30 financial ratios he believes could be useful in predicting corporate failure. ${ }^{15}$ Using 79 bankrupt and 79 nonbankrupt firms from 1954-1964 paired on asset size and industry, Beaver (1966) compares group means for each group for each of five years before failure. ${ }^{16}$ Using a cutoff score computed for each ratio to distinguish bankrupt from nonbankrupt firms, Beaver (1966) reports an overall error rate of $13 \%$ on a holdout sample, with type I errors (bankrupt predicted not to be bankrupt) higher (22\%) than type II errors (not bankrupt predicted to be bankrupt) (5\%). This study serves as the catalyst for the work in bankruptcy modeling and a multitude of studies follow, most intent on examining the question of distinguishing a healthy firm from a distressed firm using alternative methods.

\footnotetext{
${ }^{14}$ See Jones (1987) and Zavgren (1983) for comprehensive literature reviews of bankruptcy research.

${ }^{15}$ Beaver $(1966,71)$ defines failure as the "inability of a firm to pay its financial obligations as they mature." His sample includes 59 bankrupt firms, three firms that defaulted on a bond payment, 16 firms that failed to pay a preferred stock dividend, and one firm that had an overdrawn bank account.

${ }^{16}$ Beaver $(1966,77)$ defines one year before failure (year one) as the fiscal year represented by the most recent financial statements prior to the date the firm failed, and similarly for years two through five before bankruptcy.
} 
Altman (1968)

Altman's (1968) work sets the stage for the multivariate context, as it is the first to use linear multiple discriminant analysis (MDA) as a classification technique to predict bankruptcy. ${ }^{17}$ MDA finds a linear combination of variables that best separates groups into bankrupt and nonbankrupt. A cutoff score called a $z$-score is established that best separates the two groups. MDA has the advantage of considering an entire profile of characteristics of a firm, as well as the interactions of these characteristics (Altman 1968, 592). Using a sample of 33 manufacturing firms that filed a bankruptcy petition during the period 1946-1965, Altman (1968) was able to classify firms with $95 \%$ accuracy in the first year, and $72 \%, 48 \%, 29 \%$, and $36 \%$ in the second through fifth years, respectively. The independent variables were five financial ratios chosen based on their popularity in the literature and potential relevancy to the study (Altman 1968, 592). This study is important because it establishes the quality of ratio analysis as an analytical technique in bankruptcy prediction while using a multivariate statistical model.

\section{Deakin (1972)}

Deakin (1972) compares the work of Beaver $(1966,1968)$ with that of Altman (1968) with the goal of developing an MDA model that does not deteriorate with a longer lead time before bankruptcy. He uses 32 bankrupt firms from 1964-

${ }^{17}$ Some studies refer to discriminant analysis as "multiple" only when the number of classificatory groups exceeds two. In the current study "multiple" is used following the lead of Altman (1983) to refer to the multivariate nature of the analysis. 
1970 and a control sample matched not only on size and industry as Beaver (1966) did, but also on debt structure. Independent variables are Beaver's (1968) 14 financial ratios. Accuracy rates on a holdout sample for five models are: $78 \%$ for one year before bankruptcy, and $94 \%, 88 \%, 77 \%$ and $85 \%$ for years two through five, respectively. Thus, Deakin (1972) succeeds in combining MDA with Beaver's (1968) financial ratios and developing a bankruptcy prediction model with higher predictive accuracy than Altman's (1968) model in longer lead times before the year of bankruptcy. This enables managers to identify potentially failing firms and to possibly take remedial steps to avoid bankruptcy.

\section{Altman, Haldeman, and Narayanan (1977)}

The Altman, Haldeman, and Narayanan (1977) study is the first study to recognize that bankruptcy models should incorporate prior probabilities as well as the cost of misclassification into the models. That is, linear discriminant analysis establishes a cutoff at the mid-point between the two group mean scores. This cutoff automatically assumes a symmetric loss function and cost of type I and type II errors. Altman, Haldeman and Narayanan (1977) also point out that the assumptions of linear MDA may not be valid, and thus use quadratic MDA. ${ }^{18}$ Using 53 bankrupt firms and a control sample of nonbankrupt firms matched on year of bankruptcy and industry, the authors constructed linear and quadratic

\footnotetext{
${ }^{18}$ Linear MDA assumes multivariate normal populations as well as equal population covariance matrices. Quadratic MDA does not assume covariance equality and assesses the covariance of each group independently in building a model (Jones 1987, 144).
} 
discriminant functions to classify firms. Seven financial ratios were used as independent variables. The models result in a $z$-score that is then compared to a cutoff value to classify a firm as bankrupt or not. The authors find that in every comparison this new model, termed the Zeta model, is superior to the Altman (1968) model. They report classification accuracy for bankrupt firms as $96.2 \%$ for one year prior to bankruptcy and $84.9 \%, 74.5 \%, 68.1 \%$, and $69.8 \%$ for years two through five before bankruptcy, respectively. Classification accuracy for nonbankrupt firms was $89.7 \%, 93.1 \%, 91.4 \%, 89.5 \%$, and $82.1 \%$ for years one through five, respectively. This study is an important contribution to the bankruptcy modeling literature in that it incorporates prior probabilities of bankruptcy and costs of misclassification errors in an MDA model. ${ }^{19}$

Ohlson (1980)

Ohlson (1980) provides an important contribution to the bankruptcy literature in that he uses logistic regression (logit) analysis to model bankruptcy prediction. Logit is based on a cumulative probability function and does not require multivariate normality or that groups have equal covariance matrices. Estimates are found using the method of maximum likelihood. Logit is similar to MDA in that it weights the independent variables and creates a $z$-score for each company (Jones 1987, 146). The obtained $z$-score may be used to determine the probability of membership in a group where probability of bankruptcy is expressed as:

\footnotetext{
${ }^{19}$ Other studies that use MDA include Blum (1974), Dambolena and Khoury (1980), Gombola and Ketz (1983), Casey and Bartczak (1984) and Gentry, Newbold, and Whitford (1985).
} 


$$
\frac{1}{1+e^{-z}}-\frac{1}{1+e^{-\left(a+b_{1} x_{1}+\ldots+b, x_{1}\right)}}
$$

The $b$ coefficients are weighted so as to maximize the joint probability of bankruptcy for the known bankrupt firms and the probability of nonbankruptcy for the known healthy firms (Jones 1987, 146). ${ }^{20}$ Using nine financial ratios as independent variables, and a sample of 105 bankrupt and 2,058 nonbankrupt firms from 1970-1976, Ohison (1980) develops a logit model of bankruptcy prediction. He reports a type I error rate of $12.4 \%$ and a type II error rate of $17.4 \%$ for one year before bankruptcy. Tables 2 and 3 show the cutoff points and type I and type II errors from Ohlson's (1980) original model one, one year before bankruptcy and model two, two years before bankruptcy. As previously discussed, this logit model has become the benchmark against which most other bankruptcy modeling attempts are measured.

\section{Hammer (1983) and Mensah (1983)}

A number of bankruptcy modeling studies have as their primary purpose the comparison of multiple methods. For example, Hammer (1983) examines the sensitivity of classification accuracy to alternative statistical methods and variable sets using data from 44 bankrupt and nonbankrupt firms from 1966-1975. She uses predictor variables from Altman (1968), Deakin (1972), Blum (1974) and Ohlson (1980) and performs linear MDA and logit analysis. Using the chi-square statistic,

\footnotetext{
${ }^{20} \mathrm{McF}$ adden (1973) provides a detailed analysis of the logit model.
} 
she finds no statistical differences in classification accuracy between the two methods. Mensah (1983) finds similar results in comparing MDA and logit on a set of 30 bankrupt and nonbankrupt firms from 1975-1978.

\section{Begley, Ming and Watts (1995)}

Begley, Ming, and Watts (1995) attempt to resolve the issue of model superiority between Altman's (1968) discriminant analysis model and Ohlson's (1980) logit model. They compare the performance of the original models first using the original model coefficients on data from the 1980's, and second using a re-estimated, updated model with data from the 1980's. Using a sample of 99 bankrupt and 99 nonbankrupt firms matched on size and industry classification, Begley, Ming, and Watts (1995) find that Ohlson's (1980) original and re-estimated models outperform Altman's (1968) original and re-estimated models. They find that due to structural changes in the data (primarily from an increased amount of corporate leverage), the coefficients for both models changed, as well as the relative contribution of each parameter. ${ }^{21}$ Based on these findings, the current study compares the CBR's performance to the Ohlson (1980) original model and a logit model re-estimated with the same data as the CBR contains.

${ }^{21}$ For example, the estimates for the SIZE and TL/TA (total liabilities/total assets) are both significantly less negative in the re-estimated model for one year before bankruptcy, and the estimates for five of the nine variables are significantly less negative in the re-estimated model for two years before bankruptcy. 
Boritz. Kennedy and Albuquerque (1995)

In the 1980's artificial neural networks were used in bankruptcy prediction modeling. Coakley, Gammill, and Brown (1995) review studies that compare the relative predictive ability of various configurations of neural networks to other methods, including MDA and logit and conclude that inter-study comparability is inhibited by differences in architectures of neural networks. Boritz, Kennedy, and Albuquerque (1995) compare the effectiveness of a neural network designed to predict corporate bankruptcy to Altman's (1968) MDA model and OhIson's (1980) logit model. They find that classification accuracy of the various techniques depends on the proportion of bankrupt firms in the training and testing data sets, the variables used in the models, and assumptions about the relative costs of type I and type II errors (Boritz and Kennedy 1995, 16). Thus, Boritz and Kennedy (1995) are unable to draw any generalized conclusions with respect to the comparison between methods.

Boritz and Kennedy (1995)

Boritz and Kennedy (1995) extend Boritz, Kennedy, and Albuquerque (1995) by examining the impact of the type of neural network on predictive accuracy. They conclude that neural networks do not provide a dramatic improvement over more conventional techniques such as MDA and logit (Coakley, Gammill, and Brown 1995). Boritz and Kennedy (1995) also conclude that a critical area in neural network research is selection of variables because the neural network cannot in and 
of itself determine the most important variables (Boritz, Kennedy, and Albuquerque $1995,17)$.

\section{Summary}

This chapter summarizes the relevant CBR literature and discusses accounting applications of CBR. The bankruptcy literature also is summarized with emphasis on the methods used over the years to model bankruptcy. Table 1 provides a chronology of bankruptcy modeling studies. 
TABLE 1

A CHRONOLOGICAL SUMMARY OF RELEVANT BANKRUPTCY MODELING STUDIES

\begin{tabular}{|c|c|c|c|c|c|}
\hline Study & $\begin{array}{l}\text { Sample } \\
\text { Years }\end{array}$ & $\begin{array}{l}\text { Sample } \\
\text { Size } \\
\text { (Bankrupt } \\
\text { Firms) }\end{array}$ & $\begin{array}{l}\text { Predictor } \\
\text { Variables }\end{array}$ & Method & Contribution \\
\hline Beaver (1966) & $1954-64$ & 79 & 30 Ratios & Univariate & Seminal work in bankruptcy prediction. \\
\hline Altman (1968) & $1946-65$ & 33 & 5 Ratios & Linear MDA & $\begin{array}{l}\text { First study to use linear discriminant } \\
\text { analysis for bankruptcy prediction. }\end{array}$ \\
\hline Deakin (1972) & $1964-70$ & 32 & $\begin{array}{l}\text { Beaver's } \\
\text { (1968) } \\
14 \text { Ratios }\end{array}$ & Linear MDA & $\begin{array}{l}\text { Combines Beaver's (1968) univariate ratios } \\
\text { with Altman's (1968) method to achieve } \\
\text { greater predictive accuracy. }\end{array}$ \\
\hline $\begin{array}{l}\text { Altman, } \\
\text { Haldeman, } \\
\text { and Narayanan } \\
(1977)\end{array}$ & $1969-75$ & 53 & 7 Ratios & $\begin{array}{l}\text { Linear MDA } \\
\text { and Quadratic } \\
\text { MDA }\end{array}$ & $\begin{array}{l}\text { Refines model by incorporating prior } \\
\text { probabilities and cost of misclassification. } \\
\text { First to use quadratic MDA. }\end{array}$ \\
\hline Ohlson (1980) & $1970-76$ & 105 & 9 Ratios & Logit & First to use logit to predict distress. \\
\hline Hamer (1983) & $1966-75$ & 44 & $\begin{array}{l}\text { Various } \\
\text { other } \\
\text { studies }\end{array}$ & $\begin{array}{l}\text { MDA and } \\
\text { logit }\end{array}$ & $\begin{array}{l}\text { Tested sensitivity of classification } \\
\text { accuracy to alternative statistical method } \\
\text { and variable sets. Finds no difference } \\
\text { between MDA and logit. }\end{array}$ \\
\hline
\end{tabular}

(table con'd.) 


\begin{tabular}{|c|c|c|c|c|c|}
\hline Study & $\begin{array}{l}\text { Sample } \\
\text { Years }\end{array}$ & $\begin{array}{l}\text { Sample } \\
\text { Size } \\
\text { (Bankrupt } \\
\text { Firms) }\end{array}$ & $\begin{array}{l}\text { Predictor } \\
\text { Variables }\end{array}$ & Method & Contribution \\
\hline $\begin{array}{l}\text { Boritz, } \\
\text { Kennedy, and } \\
\text { Albuquerque } \\
\text { (1995) }\end{array}$ & $1971-84$ & 171 & $\begin{array}{l}\text { Altman (1968) } \\
\text { Ohlson (1980) }\end{array}$ & Neural network & $\begin{array}{l}\text { Contrasts a neural network } \\
\text { bankruptcy prediction model } \\
\text { with Altman's (1968) model } \\
\text { and Ohlson's (1980) model. } \\
\text { Fails to draw any general } \\
\text { conclusions. }\end{array}$ \\
\hline $\begin{array}{l}\text { Boritz and } \\
\text { Kennedy } \\
\text { (1995) }\end{array}$ & $1971-84$ & 171 & $\begin{array}{l}\text { Altman (1968) } \\
\text { Ohlson (1980) }\end{array}$ & Neural network & $\begin{array}{l}\text { Extension of Boritz, Kennedy, } \\
\text { and Albuquerque (1995). } \\
\text { Concludes that a neural } \\
\text { network is not a dramatic } \\
\text { improvement over more } \\
\text { conventional statistical } \\
\text { models. }\end{array}$ \\
\hline $\begin{array}{l}\text { Begley, Ming, } \\
\text { and Watts } \\
\text { (1995) }\end{array}$ & $1980-89$ & 99 & Altman (1968) & MDA and logit & $\begin{array}{l}\text { Examines the robustness } \\
\text { of Altman's (1968) model } \\
\text { and Ohlson's (1980) model } \\
\text { using 1980's data. Finds } \\
\text { Ohlson's (1980) model } \\
\text { more accurate. }\end{array}$ \\
\hline
\end{tabular}


TABLE 2

\section{RESULTS OF OHLSON'S (1980) TYPE I AND TYPE II ERROR RATES MODEL ONE, ONE YEAR PRIOR TO BANKRUPTCY ${ }^{22}$ Ohlson $(1980,130)$}

\begin{tabular}{ccc}
\hline $\begin{array}{c}\text { Estimated Probability of } \\
\text { Bankruptcy used as } \\
\text { Cutoff points }\end{array}$ & Type I & Type II \\
\hline 0.00 & $0.00 \%$ & $100.00 \%$ \\
0.02 & 7.60 & 28.70 \\
$0.04^{*}$ & 14.30 & 16.70 \\
0.06 & 20.60 & 11.60 \\
0.08 & 25.70 & 9.30 \\
0.10 & 26.70 & 7.20 \\
0.20 & 44.80 & 3.30 \\
0.30 & 48.60 & 1.75 \\
0.40 & 57.10 & 1.07 \\
0.50 & 67.60 & 0.63 \\
0.60 & 71.40 & 0.29 \\
0.70 & 76.20 & 0.19 \\
0.80 & 81.90 & 0.15 \\
0.90 & 88.60 & 0.05 \\
1.00 & $100.00 \%$ & $0.00 \%$ \\
& &
\end{tabular}

${ }^{*} 0.038$ is the cutoff point that minimizes the sum of type I and type II errors.

\footnotetext{
${ }^{22}$ Altman (1968) and Ohlson (1980) define type I and type II errors oppositely. Ohlson (1980) defines a type I error as predict bankrupt, actual nonbankrupt, while a type II error is defined as predict nonbankrupt, actual bankrupt. Altman (1968) defines a type I error to be predict nonbankrupt, actual bankrupt and a type II error as predict bankrupt, actual nonbankrupt. Begley, Ming, and Watts (1995) note this discrepancy and adopt the Altman (1968) definition of type I and type II errors. The current study also uses Altman's (1968) definition.
} 
TABLE 3

RESULTS OF OHLSON'S (1980) TYPE I AND TYPE II ERROR RATES MODEL TWO, TWO YEARS PRIOR TO BANKRUPTCY Ohlson $(1980,130)$

\begin{tabular}{ccc}
\hline $\begin{array}{c}\text { Estimated Probability of } \\
\text { Bankruptcy used as } \\
\text { Cutoff points }\end{array}$ & Type I & Type II \\
\hline 0.00 & $0.00 \%$ & $100.00 \%$ \\
0.02 & 0.00 & 54.30 \\
0.04 & 0.95 & 37.70 \\
0.06 & 4.76 & 26.80 \\
0.08 & 8.60 & 20.20 \\
0.10 & 12.40 & 17.00 \\
0.20 & 31.40 & 7.20 \\
0.30 & 43.80 & 3.60 \\
0.40 & 50.50 & 2.00 \\
0.42 & 51.40 & 1.75 \\
0.50 & 57.10 & 1.07 \\
0.54 & 61.00 & 0.82 \\
0.60 & 62.90 & 0.68 \\
0.70 & 70.50 & 0.49 \\
0.80 & 74.30 & 0.24 \\
0.90 & 82.90 & 0.19 \\
1.00 & 100.00 & 0.00 \\
\hline
\end{tabular}




\section{CHAPTER 3}

\section{RESEARCH METHOD}

The purpose of this chapter is to describe the research method and procedures used in the current study. The first section describes the research objectives and research questions. Hypotheses are developed to support the research questions, and the two phases of the project are discussed. Next, the sample selection procedures are detailed. The chapter concludes with a discussion of statistical tests performed.

\section{Research Objectives}

This research has two objectives. The primary purpose of this study is to design, develop, and test a CBR bankruptcy prediction system. Second, the CBR is compared against the benchmark model, Ohlson's (1980) logit. The two research questions are:

1. Can a CBR system be used to predict bankruptcy?

2. Is the predictive accuracy of a CBR system greater than Ohlson's (1980) nine-factor model of bankruptcy prediction?

Hypotheses are derived to test these two research questions. 


\section{Hypotheses}

The hypotheses, stated in null form, are:

$\mathrm{Ho}_{1}$ : The classification of firms by a CBR bankruptcy prediction model is independent of the actual classification of the firms as bankrupt or nonbankrupt.

$\mathrm{Ho}_{2}$ : There is no difference between the predictive accuracy of a CBR bankruptcy prediction model and Ohlson's (1980) nine-factor logit model.

The alternative hypotheses are:

$\mathrm{Ha}_{1}$ : The classification of firms by a CBR bankruptcy prediction model is not independent of the actual classification of the firms as bankrupt or nonbankrupt.

$\mathrm{Ha}_{2}$ : The CBR bankruptcy prediction model will provide greater predictive accuracy in years one through five before bankruptcy than Ohlson's (1980) nine-factor logit model.

A detailed analysis and the results of testing these hypotheses is presented in Chapter Four. This research project is conducted in two phases. Phase I involves use of the CBR shell, ReMind (Cognitive Systems 1992), to design and construct a CBR system to predict bankruptcy. ${ }^{23}$ Phase II involves testing the predictive accuracy of the CBR with Ohlson's (1980) logit model.

\footnotetext{
${ }^{23}$ In developing a CBR system, the researcher must decide whether to write the computer program from scratch or use a development tool (a shell). The decision is usually made based on the individual researcher's competency as a computer programmer. Researchers who have written the program themselves include Morris (1994), Denna et al. (1992), who adapt code from Bain's (1986a) Micro-Judge to their specific audit task, and Mukhopadhyay, Vicinanza, and Prietula (1992). Many researchers utilize CBR shells to develop their systems. These include van Zeeland (1993), Buta (1994), and Stottler (1994). There are several CBR shells in use, including ReMind (Cognitive Systems, Inc., Stamford, CT), CBR Express (Inference Corp., El Segundo, California), and Esteem (Esteem Software, Inc., Cambridge City, Indiana). ReMind was chosen for the current study due to its robust nature, thoroughness of documentation, and ease of use.
} 
Phase I: Design and Construction of the CBR System

Buta (1994) lists four major issues that must be addressed when developing a CBR system. They are case representation, indexing and retrieval, adaptation and application, and maintenance. Each will be discussed individually and defined in the context of the current study.

\section{Case Representation}

In building a library of cases that the CBR system will use to make future classifications, the developer must determine which attributes of a case are necessary and/or sufficient to make these classifications. Ideally, a theory of bankruptcy would guide the developer in choice of variables; however, because there is a lack of economic theory of bankruptcy, researchers generally choose predictor variables based on their popularity in the literature. This study follows that convention. In the current study, cases consist of frame representations of key financial ratios along with the size of the company. ${ }^{24}$ These attributes are cited in the literature as independent variables found useful in discriminating bankrupt from nonbankrupt firms. ${ }^{25}$

Table 4 presents 24 ratios found useful in previous bankruptcy studies that are used in the current study to proxy for firm-specific financial health predictors.

\footnotetext{
${ }^{24} \mathrm{~A}$ frame is a type of knowledge representation for a complex object, where the attributes that describe the object are stored in slots in the frame (Zahedi 1993, 285).

${ }^{25}$ See Beaver (1966), Chen and Shimerda (1981), Frydman, Altman, and Kao (1985), and Baldwin and Glezen (1992).
} 
These 24 financial ratios are shown by Baldwin and Glezen (1992) to have better predictive ability when compared with two reduced sets of financial ratios. ${ }^{26}$ The size variable is included because size is found to be highly significant in Ohlson's (1980) model of bankruptcy prediction.

TABLE 4

CASE ATTRIBUTES

\begin{tabular}{|c|c|c|}
\hline & Attribute & Definition of Attribute \\
\hline 1. & NI/S & Net income/Sales \\
\hline 2. & NI/TA & Net income/Total assets \\
\hline 3. & NI/NW & Net income/Net worth \\
\hline 4. & EBIT/TA & Earnings before income tax/Total assets \\
\hline 5. & S/TA & Sales/Total assets \\
\hline 6. & CA/TA & Current assets/Total assets \\
\hline 7. & QATA & Quick assets/Total assets \\
\hline 8. & S/NW & Sales/Net worth \\
\hline 9. & CA/S & Current assets/Sales \\
\hline 10. & I/S & Inventory/Sales \\
\hline 11. & COGS $/ I$ & Cost of goods sold//nventory \\
\hline 12. & TLNW & Total liabilities/Net worth \\
\hline 13. & TL/TA & Total liabilities/Total assets \\
\hline 14. & QA/S & Quick assets/Sales \\
\hline 15. & RE/I & Retained earnings/Inventory \\
\hline 16. & $\mathrm{CA} / \mathrm{CL}$ & Current assets/Current liabilities \\
\hline 17. & QA/CL & Quick assets/Current liabilities \\
\hline 18. & CL/TA & Current liabilities/Total assets \\
\hline 19. & C/TA & Cash/Total assets \\
\hline 20. & $\mathrm{C} / \mathrm{CL}$ & Cash/Current liabilities \\
\hline 21. & $\mathrm{~S} / \mathrm{C}$ & Sales/Cash \\
\hline 22. & WC/TA & Working capital/Total assets \\
\hline 23. & WC/S & Working capital/Sales \\
\hline 24. & RE/TA & Retained earnings/Total assets \\
\hline 25. & Firm size & Total assets/GNP price-level \\
\hline
\end{tabular}

${ }^{26}$ Doyle (1972) states that when using the AID clustering algorithm (discussed below), the correct approach in determining predictor variables is to explore correlations among the predictor variables and discard redundant variables. Baldwin and Glezen (1992) explore the correlations among the set of 24 financial ratios in the current study and find that the full set of 24 ratios is a better predictor of bankruptcy than two sets of ratios reduced through correlation analysis and factor analysis. Thus, the current study uses the full set of 24 ratios. 


\section{Case Indexing and Retrieval}

Case indexing, also called clustering, is the process of creating an index scheme to account for the differences in the outcome variable (bankrupt or not bankrupt). The case library must be indexed, or clustered, before the system can be used for retrieval. The index scheme created in the clustering process takes the form of a binary decision tree that when traversed, will yield a decision. Retrieval, also called matching, is the process of inputting a hypothetical case and receiving the closest matching cases from the case library.

The three major types of indexing are (1) nearest-neighbor, (2) inductive, and (3) knowledge-guided induction. In nearest-neighbor indexing, a similarity score is created and assigned to each case by the clustering algorithm. ${ }^{27}$ An input case is then compared with cases in the library, with the best scoring cases returned as possible solutions. The nearest-neighbor algorithm assumes all case attributes are equal in importance unless the developer specifies otherwise. A weight vector may be specified by the developer to improve the performance of the CBR. Knowledge-based retrieval is similar to rule-based expert systems in which an expert determines the features used to classify cases (Buta 1994, 36). Inductive indexing is a significant improvement over nearest-neighbor indexing for two reasons: First, the important features affecting the outcome are induced from the data itself, and

\footnotetext{
${ }^{27}$ To compute the similarity score, ReMind calculates the distance between input and examined field for every case in the library, based on mean and standard deviation. The calculated distance times the developer-defined field weight gives the field score. Finally, the sum of all field scores divided by the sum of all weights yields the case similarity score. (Cognitive Systems 1992)
} 
the computer system automatically generates the decision tree with the minimum number of decision nodes that can represent the data. Thus, the developer need not specify the weights for the case attributes. Second, retrieval time is faster than nearest-neighbor indexing because the cases can be organized for retrieval into a hierarchical structure that increases the retrieval time by only the log of the number of cases rather than linearly (Buta 1994, 36).

Choice of indexing method depends upon how well-defined the retrieval goal is and how many cases are available for inclusion in the case library. When the retrieval goal is well-defined and the number of cases sufficiently large, inductive indexing is the appropriate indexing technique (Barletta 1991, 4). ${ }^{28}$ When the retrieval goal is not well-defined, nearest-neighbor indexing is the appropriate indexing technique. Inductive indexing is particularly well-suited for CBR since most of our learning is through experience, which is an inductive process (Zahedi 1993, 135). Because the goal of bankruptcy prediction is well-defined, i.e., to classify a given case as bankrupt or nonbankrupt, and there is a large number of cases available for inclusion in the case library, the current study employs inductive indexing. To accomplish the indexing task, ReMind uses a clustering algorithm (discussed below) based on machine learning techniques. ${ }^{29}$ When generating the

\footnotetext{
${ }^{28}$ There is no concensus in the literature as to what constitutes a "large" number of cases. Limited guidance is provided by Hansen, Meservy, and Wood (1995), who outline a method for determining the number of cases necessary to achieve desired reliability methods.

${ }^{29}$ In rule-based systems such as expert systems, knowledge is coded into the knowledge base, and learning is static and external to the system. Efforts over the
} 
decision tree, it is important to retain a percentage of cases for use in later validation of the tree. The current study retains a portion of the sample for this purpose. Verification and validation are extremely important issues in developing a quality CBR, and are thus discussed in detail separately at the end of this chapter.

The inductive algorithm used by ReMind is based on the algorithm called Atomatic Interaction Detection (AID) (Morgan and Sonquist 1963). ${ }^{30}$ Initially there is only one cluster. The algorithm splits the $\mathrm{M}$ cases into a second cluster based on some constant $\mathrm{C}$, of a variable, $\mathrm{J}$. The choice of variable $\mathrm{J}$ to split on and the constant $C$ that serves as the threshold are chosen to minimize the sum of the squared deviations from the cluster means. The group means account for more of the total sum of squares of the dependent variables than the means of any other combination of predictor variables (Heald 1972, 452). Hartigan $(1975,337)$ describes the clustering process as follows:

past ten years have focused on developing systems that could learn automatically. This body of research is known as machine learning, and includes work in CBR and neural networks. (Zahedi 1993, 538-539).

${ }^{30}$ The type of algorithm was ascertained per discussion with Dr. Marc Goodman (Continuum Software, Inc.), the project leader for the team that designed ReMind. According to Dr. Goodman, there is no research that documents the exact algorithm. The AID program was developed at the Institute of Social Research, University of Michigan, in 1963. 
During the algorithm, the clusters are numbered 1, 2 ,...,KC. The cluster $K$ splits into two clusters $\mathrm{L} 1(\mathrm{~K})$ and $\mathrm{L} 2(\mathrm{~K})$, where $\mathrm{L} 2(\mathrm{~K})>\mathrm{L} 1(\mathrm{~K})>\mathrm{K}$. The number of cases in cluster $\mathrm{K}$ is $N C(K)$. The average value of $A(I, 0)$ over cases in cluster $K$ is AVE(K). The between-cluster sum of squares at cluster $K$ is

$$
\operatorname{SSQ}(\mathrm{K})=\frac{[\operatorname{AVE}(\mathrm{L} 2(\mathrm{~K}))-\operatorname{AVE}(\mathrm{L} 1(\mathrm{~K}))]^{2}}{1 / \mathrm{NC}(\mathrm{L} 2(\mathrm{~K}))+1 / \mathrm{NC}(\mathrm{L} 1(\mathrm{~K}))}
$$

At each stage, whichever cluster has the smallest value of $\mathrm{SSQ}(\mathrm{K})$ is split, and the two subclusters $\mathrm{L} 1(\mathrm{~K})$ and $\mathrm{L} 2(\mathrm{~K})$ become available for further splitting.

The splitting will continue until KC clusters are obtained. If $\mathrm{KC}$ is chosen somewhat larger than the number of clusters expected, the later splits may be rejected after examination of the tree ...

Cutoff points for each variable (as determined by the clustering algorithm) are shown in each node. Every branch of the tree ends in a terminal node where actual cases are stored. Examination of a given terminal node reveals the cases stored there. Generally the tree is pruned to prevent the algorithm from overfitting the data such that one case appears at each terminal node. The relative importance of variables can be observed by inspection of the tree.

\section{Adaptation and Application}

Adaptation is the process of adjusting the retrieved cases to fit the current case. For cases with a quantitative outcome variable, adaptation, through the use of formulas, is a critical step because cases retrieved by the system rarely match the input case exactly. However, for classification tasks, adaptation is not applicable and therefore is not used here. The input case is classified as bankrupt or not 
bankrupt on the basis of the majority of cases retrieved as a result of the inductive retrieval process.

\section{Maintenance}

Maintenance of a CBR system involves updating the case library as future cases that provide additional decision-making power are encountered and resolved. One of the distinct advantages of CBR over rule-based systems and neural networks is that updating the case library is easily accomplished by adding a new case. This knowledge is in turn used to make future classification decisions. Additionally, uniform changes to the case library such as adding a new attribute can be easily done and the case library reclustered on the new information. Other maintenance issues, more of a managerial nature, include designating someone to be the CBR librarian and determining how frequently the library is updated (Buta 1994, 37). Other important issues include verifying the completeness and correctness of the CBR system. These are verification and validation issues and are addressed below. Adrion, Branstad, and Cherniavsky (1982) define verification as "the demonstration of the consistency, completeness and correctness of the software." O'Leary (1993) discusses his definitions of these components of verification. The current study relies on O'Leary's (1993) definitions of consistency, completeness and correctness. These components will be discussed in the context of the current study individually. 


\section{Consistency}

O’Leary $(1993,58)$ defines consistency in case-based systems as "parallel implementation of parallel structures, whether those structures are words or relations between cases, such as trees." In the context of this study, consistency is achieved by symmetry of case attributes. All attributes are expressed in ratio form and are thus parallel in structure. Additionally, there are the same number of attributes per case, further ensuring a consistent structure.

\section{Completeness}

According to O'Leary $(1993,62)$, completeness of the cases that comprise the case library can be assessed by examination of two distributions. First, the distribution of slot contents per case can reveal anomalous case attributes. This is accomplished in the current study by developing a distribution of the number of slots in each case with nil (blank) contents. Ideally, every case should have all attributes present. In the event of missing data for a given field, however, the contents of that attribute would show nil (no value). For example, each case has 25 attributes consisting of the 24 financial ratios plus the size of the firm scaled by GNP. If a given company is missing data such that ten ratios reflect no value, then $10 / 25$ or $40 \%$ of the frames would be blank. Distributions are developed to determine the average percent of frames blank for each case and cases with an unacceptable number of cases blank are discarded. The second completeness distribution discussed by O'Leary $(1993,62)$ is the distribution of contents per slot across cases. For example, there are approximately 2,100 cases that comprise the 
case library. If $1,050 / 2,100$ cases $(50 \%)$ are missing a certain financial ratio, this indicates a completeness problem. Recognition of the problem can alert the developer to examine the data set for input errors or other possible causes of the high percentage of missing data.

\section{Correctness}

Verifying the correctness of the data is another critical issue in development of the CBR. The data are verified in the current study by a utilization of a series of ReMind editing routines and input validation checks. These include use of field checks such as "field type" and reasonableness checks such as "legal minimum" and "legal maximum." For example, at the design stage, the developer must specify whether a field is designed for an integer, real number, symbol (text), or boolean (true/false) value. Subsequently, at the input stage, the program will not allow a field type other than the pre-specified field type to be entered. The reasonableness checks work similarly. For example, size of the company is a number that should always be positive, since it is based on total assets of the company. ${ }^{31}$ Therefore, the legal minimum for this field is specified as 1 , or one dollar.

\section{Validation of the CBR}

Adrion, Branstad, and Cherniavsky (1982) define validation as "the determination of the correctness of the final program or software produced from a development project with respect to the user needs and requirements." Thus,

\footnotetext{
${ }^{31}$ The sampling procedure used in the current study was designed to select only firms that had positive assets. See "Sample Selection and Data Collection" below for a full discussion of the sampling procedure.
} 
validation consists of ensuring the ex post accuracy of the CBR system. In CBR, validation has generally been accomplished by comparing the CBR with either a human expert (Morris 1994), a mathematical model (Mukhopadhyay, Vicinanza, and Prietula 1992), or known case outcomes (Denna et al. 1992). The current study validates the CBR by comparing its predictive accuracy to Ohlson's (1980) logit model, which has been shown to be the most accurate statistical model of bankruptcy prediction currently in use. Phase II of this paper discusses in detail the comparison of CBR and logit.

Another critical validation issue deals with the creation of the decision tree during the inductive indexing process and estimation of the accuracy of the CBR model. It is not sufficient to judge the predictive accuracy of the CBR based on one decision tree only because choice of the cases to be stored may significantly change the resultant decision tree. Additionally, the developer must take care that subsequent testing is performed with samples drawn independently from the same population as the sample used to generate the tree. Breiman et al. $(1984,10)$ demonstrate that this problem is of little consequence when using simulated data. After constructing a classifier, $\mathrm{d}(\mathrm{x})$, they draw 5,000 additional cases from the same distribution independently of their learning sample, L. An estimate of the true misclassification rate $R^{*}(d)$, is the proportion misclassified among those 5,000 additional cases. Breiman et al. (1984) point out that in the real world, only the data in $L$ are available, and $L$ must therefore be used to construct $d(x)$ and to estimate $R^{*}(d)$. 
Breiman et al. (1984) suggests three methods for estimation of $R^{\circ}(d)$ : resubstitution, test sample, and V-fold cross validation. Of the three methods, the V-fold cross-validation procedure is the method chosen for the current study. ${ }^{32}$ This method was chosen because it is more accurate than resubstitution and does not have the limiting effect on the sample size that the test sample method does (see footnote 31 ). The $\mathrm{V}$-fold method requires that the learning sample, $\mathrm{L}$, be subdivided into $\mathrm{V}$ subsets $\left(\mathrm{L}_{1}, \ldots \mathrm{L}_{\mathrm{v}}\right)$ of an equal number of cases. For every $\mathrm{v}$, $v=1, \ldots V$ a classifier is developed using $L-L_{v}$. Subsequent to development of the classifier, the cases in $\mathrm{L}_{\overrightarrow{ }}$ are used to determine the predictive accuracy of the system. Thus, $\mathrm{L}_{\mathrm{v}}$ is treated as a holdout sample. The process is repeated for every subset, $\mathrm{L}_{\nabla}$. For the current study, the case library consists of 2,085 cases. Of these 2,085 cases, 514 are retained for a designated purpose (discussed in the following paragraph). The remaining 1,571 cases, $\mathrm{L}$, are divided into ten equal subsets, $\mathrm{v}$, consisting of 157 randomly chosen cases each. ${ }^{33}$ Ten different CBR models are

\footnotetext{
${ }^{32}$ Breiman et al. $(1984,10)$ provides details of the other two methods, the resubstitution estimate and the test sample estimate. The resubstitution estimate is achieved by constructing a classifier $d(x)$ first using all cases in the learning sample, L. Next, the cases in $L$ are substituted back into $d(x)$ and the proportion of cases misclassified is the resubstitution estimate. This method is the least accurate of the three methods and can give overly optimistic estimates of the accuracy of $d(x)$ (Breiman et al. 1984, 11). In the test sample method, the cases in L are divided into two sets of cases $L_{1}$ and $L_{2}$, usually $2 / 3-1 / 3$ split. The cases in $L_{1}$ are used to construct the classifier, $d(x)$, while the cases in $L_{2}$ are used to test the accuracy of $\mathrm{d}(\mathrm{x})$. The disadvantage of this method is that it reduces the effective sample size (Breiman et al. 1984, 11).

${ }^{33}$ Breiman et al. $(1984,85)$ report that taking $V=10$ gives adequate accuracy, and that they did not come across any situations where taking $V$ larger than 10 gave a significant improvement in accuracy. Thus, $V=10$ is used in this study.
} 
constructed by systematically leaving out one subset, $L_{r}$ and creating the decision tree with the remaining cases. ${ }^{34}$ The subset of cases, $L_{r}$ is then used to determine the predictive accuracy of the tree. This process is repeated ten times, once for each subset of cases. The ten error rates are averaged, and the results provide an estimate of the true misclassification rate, $R^{\prime}(d)$.

One additional test of accuracy is performed. This test uses the 514 cases retained as an out-of-period holdout sample. Begley, Ming, and Watts (1995) demonstrate the degeneration of the accuracy of both Altman's (1968) MDA model of bankruptcy prediction as well as Ohlson's (1980) logit model when tested on data from outside the time period from which the models are created. ${ }^{35}$ Because of the apparent degeneration of the models when future data is used for validation, the current study sets aside all cases from 1990-1994 as a holdout sample to test the models for accuracy outside of the time periods of the data used to create the models. This holdout sample consists of 500 nonbankrupt firms (100 from each of

${ }^{34}$ Creating the ten CBR models can be accomplished in ReMind by using an option called a view. Views allow alternative trees to be created using one CBR case library.

${ }^{35}$ For example, Altman's (1968) model reports $95 \%$ overall accuracy rate one year before bankruptcy and a $83 \%$ overall accuracy rate two years prior to bankruptcy. Begley, Ming, and Watts (1995) show that in using 1980's data in the original MDA model, the overall accuracy drops to $72 \%$ and $69 \%$ for one year and two years prior to bankruptcy, respectively. Ohlson (1980) reports type I and type II errors as $12.4 \%$ and $17.4 \%$, respectively, for one year prior to bankruptcy. Begley, Ming, and Watts (1995) again demonstrate the degeneration of the model. In using 1980's data in the Ohison's (1980) original model, type I and type II errors rise to $14 \%$ and $23.5 \%$, respectively, for one year prior to bankruptcy. A similar loss of accuracy is noted for two years prior to bankruptcy. 
1990-1994) and 14 bankrupt firms from 1990-1994. The remaining 1,414 firms are used to create a decision tree, with the 514 cases then used to determine the predictive accuracy of the CBR. This process is also in keeping with Doyle's (1972, 466) suggestion that bias in the model-building process can be mitigated by splitting the sample, using one part for analysis and the other part for validation, and provides another validation test of the CBR's accuracy.

\section{Phase II: CBR Compared to Logit}

In Phase II, a comparison is made between the predictive accuracy of the newly created CBR and Ohlson's (1980) nine-factor logit model. The purpose of this comparison is to determine which method yields the highest predictive accuracy, which would test research question two. Thus, the accuracy of each model is quantified and compared.

In comparing the accuracy of the two methods, it is not appropriate to compare the newly created CBR model with Ohlson's (1980) original model. This is because that model is developed with data from 1970-1976, while the CBR developed in the current study is developed using data from 1975-1989. Therefore, observed differences in predictive accuracy could be artifacts of temporal differences in the data. In order to avoid confounding the comparison of methods, Ohlson's (1980) nine factor logit model is re-estimated with the identical data from the CBR. The dependent variable in the logit model is the binary outcome classification of a firm as bankrupt or not bankrupt. This re-estimated model provides an updated version of Ohlson's (1980) logit model using the same data as comprise the CBR 
case library. Table 5 provides a summary of the expected signs of the logit variables based on Ohlson (1980).

TABLE 5

DESCRIPTION OF OHLSON (1980) VARIABLES

\begin{tabular}{|c|c|c|}
\hline Variable & Description & $\begin{array}{l}\text { Expected } \\
\text { Sign }\end{array}$ \\
\hline SIZE & $\begin{array}{l}\text { In(total assets/GNP price-level } \\
\text { index). The index assumes a base } \\
\text { value of } 100 \text { for } 1968 .\end{array}$ & - \\
\hline TLTA & total liabilities/total assets & + \\
\hline WC/TA & working capital/total assets & - \\
\hline $\mathrm{CL} / \mathrm{CA}$ & current liabilities/current assets & + \\
\hline OENEG & $\begin{array}{l}\text { one if total liabilities exceed total } \\
\text { assets, else zero; a discontinuity } \\
\text { correction for TLTA. }\end{array}$ & $?$ \\
\hline NI/TA & net income/total assets & - \\
\hline FU/TL & $\begin{array}{l}\text { funds provided by operations/ } \\
\text { total liabilities }\end{array}$ & - \\
\hline INTWO & $\begin{array}{l}\text { one if net income was negative for } \\
\text { last two years, else zero }\end{array}$ & + \\
\hline CHIN & $\begin{array}{l}\text { one year percentage change in net } \\
\text { income }\end{array}$ & - \\
\hline
\end{tabular}




\section{Sample Selection and Data Collection}

This study is limited to manufacturing and retailing firms (SIC codes less than 4000 and between 5000 and 5999). This focus excludes industries such as banks, insurance companies, REITs, because they have a different bankruptcy environment, and data may not be readily available. A sample of 85 bankrupt manufacturing and industrial firms from $1975-1994$ is obtained by writing fortran programs to access the annual Compustat research and industrial databases by deletion code..$^{36,37}$ The sample firms are checked to verify the existence of total assets. Each company's bankruptcy filing date is obtained by examination of Moody's Directory of Obsolete Securities, Who Audits America, and the Capital Changes Reporter in order to verify that the bankruptcy filing date follows the fiscal year end by at least four months. ${ }^{38}$ This check is necessary to ensure that bias is not created in the models by using financial statements created with the knowledge

\footnotetext{
${ }^{36}$ The use of a long sample period has been widely practiced in bankruptcy research. Table 1 reports the span of sample years in a select group of bankruptcy studies. For the most part, these studies have ignored possible structural changes in the economy or data. Studies that attempted to consider price level adjusted data include Norton and Smith (1979), which found no difference in price level adjusted data and historical cost data, and Mensah (1983), which found that price level adjusted data may be valuable when costs of misclassification were considered.

${ }^{37}$ Deletion code two indicates Chapter 11 bankruptcy and deletion code three indicates Chapter 7 bankruptcy.

${ }^{38}$ Thirty-one bankruptcy filing dates were provided by Dr. Joy Begley of the University of British Columbia pursuant to the Begley, Ming, and Watts (1995) research, which paralleled the current study in part.
} 
that this company had filed for bankruptcy (Ohlson 1980). ${ }^{39}$ Consistent with Ohlson (1980) and Begley, Ming, and Watts (1995), if the bankruptcy filing date occurs within four months following the fiscal year end, the previous year's financial statements are treated as the last financial statements available prior to bankruptcy and are used in model one.

For each of the bankrupt firms three years of data are collected, including year one before bankruptcy, year two before bankruptcy and year three before bankruptcy. The raw data are imported into a spreadsheet and 24 financial ratios for each of the three years are created and stored (by year) along with a size ratio in three text files. These 25 ratios are then imported into the ReMind program and subsequently provide the cases for the bankrupt firms.

The sample of nonbankrupt manufacturing and industrial firms consists of 100 firms randomly selected from Compustat for each year from 1975 to 1994, for a total of 2,000 firms. A vector of financial information is gathered from Compustat and imported into a spreadsheet where the 25 financial ratios are created and

${ }^{39} \mathrm{~A}$ major contention of Ohlson (1980) is that prior bankruptcy prediction models achieve high accuracy rates due in part to the sampling procedures of those studies. Ohlson (1980) points out almost all studies used Moody's Manual to derive a sample of bankrupt firms, and thus the exact date of the financial statements release to the public is unobservable. Ohlson (1980) uses 10-K financial statements and thus can observe the date of release to the public. Ohlson (1980) maintains that this failure to consider the timing issue is not a trivial problem and may in fact lead to "back-casting" for many of the failed firms" (Ohlson 1980, 110). Begley, Ming, and Watts (1995) examine 165 bankrupt firms and find that all bankruptcy filings occurring less than four months after the fiscal year end are likely to have occurred prior to the earnings announcement (Begley, Ming and Watts 1995, 8). Consistent with Begley, Ming, and Watts (1995), the current study adopts this four month criteria to establish the last financial statements prior to bankruptcy. 
stored in a text file. These ratios are then imported into ReMind and provide the cases for the nonbankrupt firms.

\section{Statistical Tests}

Phase I statistical tests requires creation of $2 \times 2$ contingency tables of actual classifications against predicted classifications. The CBR's accuracy is judged to be the mean predictive accuracy from the 10 views created from the 1975-1989 data. A classification matrix is constructed consisting of correct classifications ("hits") and incorrect classifications ("misses"). Prediction error rates for bankrupt and nonbankrupt firms are calculated. Next, in order to validate the system with data from outside the time period used to create the CBR, the cases from 1990-1994 are used to create $2 \times 2$ contingency tables and prediction error rates for bankrupt and nonbankrupt firms are calculated.

Tests of $\mathrm{Ho}_{2}$ similarly involve construction of a classification matrix to compare hits and misses for the CBR model to hits and misses for the logit model. Chi-square statistics are calculated on the CBR accuracy compared with the logit accuracy. Results of these tests are reported in Chapter 4.

Phase II involves re-estimating the Ohlson (1980) logit model to test its predictive accuracy against the CBR. The model estimated is:

$$
\mathrm{Y}=\mathrm{f}(\mathrm{SIZE}, \text { TLTA, WCTA, CLCA, OENEG, NITA, FUTL, INTWO, CHIN) }
$$

where $\mathrm{Y}=0$ if the firm does not go bankrupt, and

$Y=1$ if the firm does go bankrupt. 
A statistically significant coefficient for any of the independent variables indicates that the variable has an effect on the probability that the firm will go bankrupt. Type I and type II errors are determined by choosing a cutoff point that minimizes the sum of the type I and type II errors as the estimated probability of bankruptcy.

$\underline{\text { Summary }}$

This chapter describes the method and procedures used in the current study. The research questions are stated and two hypotheses are developed. The four main issues in developing the CBR are presented and discussed, as well as the ReMind clustering algorithm. The sample selection procedures are detailed and statistical tests presented. Chapters Four and Five, respectively, will present the data analysis and conclusions of the study. 


\section{CHAPTER 4}

\section{RESULTS}

This chapter presents the results of the CBR and logit analyses described in Chapter 3. The sample selection procedures are described first, followed by a discussion of the univariate statistics. The CBR analysis is discussed next, followed by a description of the logit statistical tests. The chapter concludes with a comparison of CBR error rates with logit error rates.

\section{Sample Selection Procedures}

Table 6 provides a summary of the sample selection procedures for the bankrupt firms. The primary data sources for the nonbankrupt firms are Compustat's 1994 Annual Industrial Primary-Supplementary-Tertiary File and 1994 Over-the-Counter File, which provide annual historical data for 20 years on publicly traded firms. Data for the bankrupt firms were obtained from the 1994 Annual Primary-Supplementary-Tertiary Industrial Research Files and 1994 Over-the-Counter Research File. ${ }^{40}$ Only manufacturing and industrial firms are included in the study because financial ratios of finance, utility, insurance, and service industries are not comparable. The initial search yielded 133 bankrupt firms classified by Compustat

\footnotetext{
${ }^{40}$ Compustat's Full-Coverage File is not used because Louisiana State University does not subscribe to this file.
} 
as manufacturing or industrial. Forty-eight firms were discarded for the reasons shown in Table 6. Three years of consecutive data were needed to compute ratios for models one, two, and three. Bankruptcy filing dates were required to compare the filing date with the fiscal year end to ensure that the filing date did not fall within four months of the fiscal year end.

TABLE 6

SAMPLE SELECTION OF BANKRUPT FIRMS

Number of firms from Compustat that meet SIC code criteria and footnote code criteria

Less: Firms that do not have at least three consecutive years of data

Firms for which bankruptcy filing

dates could not be verified

Firms for which bankruptcy filing date occur less than four months following fiscal year end

Final sample of bankrupt firms

$\underline{85}$

Ohlson $(1980,110)$ states that failure to consider this timing issue may lead to "back-casting" for many bankrupt firms (refer to footnote 39 for discussion of "back-casting" in the context of Ohlson 1980). In this study bankruptcy filing dates were obtained by examination of Moody's Directory of Obsolete Securities, Who Audits America, and the Capital Changes Reporter. Twelve firms were found to have bankruptcy filing dates that occurred less than four months following the company's 
fiscal year end. Two of the twelve firms had enough years of data to enable calculation of three years of ratios, treating the previous year's financial statements as the last financial statements available prior to bankruptcy. The remaining ten firms did not have sufficient data to calculate three years of ratios and are discarded. The Compustat data were imported into four Excel spreadsheets, one for each year prior to bankruptcy and one for calculation of the logit variables. The 25 ratios used in the case library were calculated as well as the nine logit variables necessary to fit the logit model.

The distribution of years of bankruptcy filing is shown in Table 7. The distribution is skewed towards the late 1970 s and early 1980 s, with $52 \%$ of the sample firms filing bankruptcy by 1982 . This distribution is consistent with Dun and Bradstreet's Business Failure Record (1982), which reports a dramatic increase in bankruptcies during this time period. One hundred nonbankrupt manufacturing and industrial firms from each of the 20 years on the Compustat database were randomly selected using a $S A S$ macro procedure. ${ }^{41}$ Each firm is represented by a single vector of financial data for a given year. The $S A S$ macro prevents a firm from being selected twice in the selection procedure. These data were imported into two Excel spreadsheets, one for use in the CBR case library, and one for use in the logit model.

${ }^{41} S A S$ is a statistical analysis system owned by the SAS Institute, Inc., Cary, North Carolina. 
TABLE 7

\section{DISTRIBUTION OF YEARS OF BANKRUPTCY FILING FOR 85 BANKRUPT FIRMS}

\begin{tabular}{cc}
\hline Year of Bankruptcy Filing & Number of Firms \\
\hline 1978 & 6 \\
1979 & 9 \\
1980 & 10 \\
1981 & 12 \\
1982 & 8 \\
1983 & 3 \\
1984 & 6 \\
1985 & 5 \\
1986 & 7 \\
1987 & 1 \\
1988 & 1 \\
1989 & 7 \\
1990 & 2 \\
1991 & 7 \\
1992 & 2 \\
1993 & 1 \\
1994 & 2 \\
& $\underline{85}$
\end{tabular}

Twenty-five ratios were calculated for the case library, and nine were calculated for the logit model.

\section{Descriptive Statistics}

Table 8 presents means and standard deviations for the 25 CBR variables and the nine logit variables. ${ }^{42}$ Refer to Tables 4 and 5 (in Chapter 3) for

${ }^{42}$ The ratios presented in Table 8 represent variable means after truncation of outliers. SAS's PROC UNIVARIATE is run to determine the presence of outliers for each variable. The variable with the most outliers truncated is Sales/Cash, with 12 outliers truncated or $.006 \%$ of the total observations for that variable. 
descriptions of the CBR variables and the logit variables, respectively. Two-tailed t-tests of the difference in group means between the nonbankrupt firms and the bankrupt firms in model one, one year before bankruptcy, show that the differences in means for most variables are statistically significant. C/CL and SIZE are the most significant variables, with t-statistics of 8.26 and 8.01 , respectively. This finding is consistent with Ohlson (1980) and Beaver (1966), who both find these variables to be highly significant. Other variables where the difference between bankrupt and nonbankrupt firms is highly significant are NI/TA, EBIT/TA, QATA, CA/S, TL/TA, QA/S, WC/S, INTWO, and CHIN. These variables include measures of cash flow (C/CL), net income ratios (NI/TA, EBIT, INTWO, CHIN), a liquid asset ratio (QA/TA), a turnover ratio (CA/S, WC/S), and a debt ratio (TL/TA). Thus, variables from several categories of financial ratios have means that are significantly different between bankrupt and nonbankrupt firms. One surprising finding is that the group means for the current ratio, CAVCL, are not significantly different. The current ratio is one of the the most closely scrutinized liquidity ratios; however, the t-test for a difference in means returns a test statistic of 1.40 , which is not significant at conventional levels. Another commonly used liquidity variable is QA/CL, or quick assets (current assets minus inventory) divided by current liabilities. This variable also fails to reach statistical significance at conventional levels, with a t-statistic of 1.23. Two sales ratios, S/TA and S/NW, both fail to reach statistical significance at conventional levels, with t-statistics of -1.30 and -.49 respectively. This finding is 
unexpected because bankruptcy often is tied to inadequate sales (Business Failure Record 1983, 20). Multivariate CBR and logit analyses are provided next.

TABLE 8

DESCRIPTIVE STATISTICS

CBR AND LOGIT VARIABLES ${ }^{2}$

\begin{tabular}{|c|c|c|c|c|c|}
\hline & \multirow[b]{2}{*}{$\begin{array}{l}\text { Nonbankrupt } \\
\text { Firms }\end{array}$} & \multicolumn{4}{|c|}{ Bankrupt Firms } \\
\hline & & $\begin{array}{l}\text { Model } \\
\text { One }\end{array}$ & $\begin{array}{l}\text { Model } \\
\text { Two }\end{array}$ & $\begin{array}{l}\text { Model } \\
\text { Three }\end{array}$ & \\
\hline Variable & $\begin{array}{l}\text { Mean } \\
\text { (SD) }\end{array}$ & $\begin{array}{l}\text { Mean } \\
\text { (SD) }\end{array}$ & $\begin{array}{l}\text { Mean } \\
\text { (SD) }\end{array}$ & $\begin{array}{l}\text { Mean } \\
\text { (SD) }\end{array}$ & $t$-test $t^{b}$ \\
\hline$\overline{\text { SIZE }^{c}}$ & 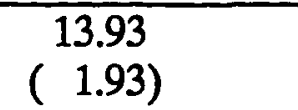 & $\begin{array}{c}12.79 \\
(1.25)\end{array}$ & $\begin{array}{c}12.82 \\
(1.20)\end{array}$ & $\begin{array}{c}12.75 \\
(1.18)\end{array}$ & $\overline{8.01^{d}}$ \\
\hline NI/S & $\begin{array}{c}-.04 \\
(.87)\end{array}$ & $\begin{array}{c}-.07 \\
(.22)\end{array}$ & $\begin{array}{c}-.03 \\
(.17)\end{array}$ & $\begin{array}{c}-.04 \\
(.24)\end{array}$ & .97 \\
\hline $\mathrm{NI} / \mathrm{TA}^{\mathrm{c}}$ & $\begin{array}{l}.04 \\
(.20)\end{array}$ & $\begin{array}{c}-.09 \\
(.22)\end{array}$ & $\begin{array}{c}-.02 \\
(.15)\end{array}$ & $\begin{array}{c}-.02 \\
(.20)\end{array}$ & $5.27^{\mathrm{d}}$ \\
\hline NI/NW & $\begin{array}{c}.10 \\
(1.49)\end{array}$ & $\begin{array}{c}.01 \\
(1.59)\end{array}$ & $\begin{array}{c}-.14 \\
(2.13)\end{array}$ & $\begin{array}{l}.03 \\
(.50)\end{array}$ & .52 \\
\hline EBIT/TA & $\begin{array}{l}.08 \\
(.21)\end{array}$ & $\begin{array}{c}-.07 \\
(.23)\end{array}$ & $\begin{array}{l}.00 \\
(.17)\end{array}$ & $\begin{array}{l}.00 \\
(.20)\end{array}$ & $5.83^{\mathrm{d}}$ \\
\hline S/TA & $\begin{array}{c}1.44 \\
\left(\begin{array}{c}.98 \\
)\end{array}\right)\end{array}$ & $\begin{array}{l}1.60 \\
(1.10)\end{array}$ & $\begin{array}{l}1.60 \\
(1.09)\end{array}$ & $\begin{array}{l}1.57 \\
(1.14)\end{array}$ & -1.30 \\
\hline CA/TA & $\begin{array}{l}.56 \\
(.22)\end{array}$ & $\begin{array}{l}.56 \\
(.24)\end{array}$ & $\begin{array}{l}.56 \\
(.23)\end{array}$ & $\begin{array}{l}.57 \\
(.22)\end{array}$ & .07 \\
\hline QA/TA & $\begin{array}{l}.29 \\
(\quad .18)\end{array}$ & $\begin{array}{l}.23 \\
(.14)\end{array}$ & $\begin{array}{l}.24 \\
(.15)\end{array}$ & $\begin{array}{l}.243 \\
(.15)\end{array}$ & $3.51^{\mathrm{d}}$ \\
\hline S/NW & $\begin{array}{l}3.25 \\
(5.88)\end{array}$ & $\begin{array}{c}3.91 \\
(12.22)\end{array}$ & $\begin{array}{c}5.79 \\
(14.80)\end{array}$ & $\begin{array}{l}4.13 \\
(4.93)\end{array}$ & -.49 \\
\hline $\mathrm{CA} / \mathrm{S}$ & $\begin{array}{c}.81 \\
(3.23)\end{array}$ & $\begin{array}{l}.48 \\
(.40)\end{array}$ & $\begin{array}{l}.42 \\
(.22)\end{array}$ & $\begin{array}{l}.44 \\
(.21)\end{array}$ & $3.88^{\mathrm{d}}$ \\
\hline I/S & $\begin{array}{l}.20 \\
(.34)\end{array}$ & $\begin{array}{l}.21 \\
(.25)\end{array}$ & $\begin{array}{l}.19 \\
(.20)\end{array}$ & $\begin{array}{l}.20 \\
(.17)\end{array}$ & -.38 \\
\hline COGS/I & $\begin{array}{l}6.81 \\
(8.98)\end{array}$ & $\begin{array}{l}7.76 \\
(7.64)\end{array}$ & $\begin{array}{l}7.26 \\
(7.66)\end{array}$ & $\begin{array}{l}6.58 \\
(7.72)\end{array}$ & -1.08 \\
\hline
\end{tabular}




\begin{tabular}{|c|c|c|c|c|c|}
\hline & & & nkrupt Fir & & \\
\hline & $\begin{array}{l}\text { Nonbankrupt } \\
\text { Firms }\end{array}$ & $\begin{array}{l}\text { Model } \\
\text { One }\end{array}$ & $\begin{array}{l}\text { Model } \\
\text { Two }\end{array}$ & $\begin{array}{l}\text { Model } \\
\text { Three }\end{array}$ & \\
\hline Variable & $\begin{array}{l}\text { Mean } \\
\text { (SD) }\end{array}$ & $\begin{array}{l}\text { Mean } \\
\text { (SD) }\end{array}$ & $\begin{array}{l}\text { Mean } \\
\text { (SD) }\end{array}$ & $\begin{array}{l}\text { Mean } \\
\text { (SD) }\end{array}$ & t-test ${ }^{b}$ \\
\hline TLNWW & $\begin{array}{c}1.22 \\
(12.91)\end{array}$ & $\begin{array}{l}1.23 \\
(6.79)\end{array}$ & $\begin{array}{l}1.60 \\
(7.87)\end{array}$ & $\begin{array}{l}1.66 \\
(3.10)\end{array}$ & -.01 \\
\hline $\mathrm{TL} / \mathrm{TA}^{\mathrm{c}}$ & $\begin{array}{l}.50 \\
(.26)\end{array}$ & $\begin{array}{l}.72 \\
(.42)\end{array}$ & $\begin{array}{l}.63 \\
(.32)\end{array}$ & $\begin{array}{r}.59 \\
(.24)\end{array}$ & $-4.70^{d}$ \\
\hline QA/S & $\begin{array}{c}.54 \\
(2.71)\end{array}$ & $\begin{array}{l}.20 \\
(\quad .18)\end{array}$ & $\begin{array}{l}.20 \\
(.17)\end{array}$ & $\begin{array}{l}.20 \\
(.15)\end{array}$ & $5.30^{\mathrm{d}}$ \\
\hline $\mathrm{RE} / \mathrm{I}$ & $\begin{array}{c}1.27 \\
(11.28)\end{array}$ & $\begin{array}{c}.57 \\
(8.07)\end{array}$ & $\begin{array}{r}.90 \\
(6.17)\end{array}$ & $\begin{array}{c}.76 \\
(5.98)\end{array}$ & .76 \\
\hline $\mathrm{CA} / \mathrm{CL}$ & $\begin{array}{l}2.96 \\
(7.89)\end{array}$ & $\begin{array}{l}2.24 \\
(4.34)\end{array}$ & $\begin{array}{l}2.06 \\
(1.31)\end{array}$ & $\begin{array}{l}2.12 \\
(1.11)\end{array}$ & 1.40 \\
\hline QA/CL & $\begin{array}{l}1.64 \\
(2.70)\end{array}$ & $\begin{array}{l}1.16 \\
(3.44)\end{array}$ & $\begin{array}{l}.98 \\
(.99)\end{array}$ & $\begin{array}{l}1.04 \\
(1.31)\end{array}$ & 1.23 \\
\hline CL/TA & $\begin{array}{l}.27 \\
(.19)\end{array}$ & $\begin{array}{l}.40 \\
(.24)\end{array}$ & $\begin{array}{l}.35 \\
(\quad .24)\end{array}$ & $\begin{array}{l}.31 \\
(.17)\end{array}$ & $-5.02^{d}$ \\
\hline C/TA & $\begin{array}{c}.12 \\
(.16)\end{array}$ & $\begin{array}{l}.06 \\
(.08)\end{array}$ & $\begin{array}{l}.07 \\
(.09)\end{array}$ & $\begin{array}{l}.07 \\
(\quad .08)\end{array}$ & $6.66^{\mathrm{d}}$ \\
\hline $\mathrm{C} / \mathrm{CL}$ & $\begin{array}{c}.90 \\
(2.30)\end{array}$ & $\begin{array}{l}.27 \\
(.49)\end{array}$ & $\begin{array}{c}.34 \\
(\quad .48)\end{array}$ & $\begin{array}{l}.37 \\
(.54)\end{array}$ & $8.26^{d}$ \\
\hline S/C & $\begin{array}{r}67.75 \\
(157.37)\end{array}$ & $\begin{array}{c}94.14 \\
(126.35)\end{array}$ & $\begin{array}{c}65.77 \\
(103.22)\end{array}$ & $\begin{array}{c}130.02 \\
(435.05)\end{array}$ & $-1.80^{f}$ \\
\hline WC/TA & $\begin{array}{l}.29 \\
(\quad .25)\end{array}$ & $\begin{array}{l}.16 \\
(.29)\end{array}$ & $\begin{array}{l}.20 \\
(.32)\end{array}$ & $\begin{array}{r}.24 \\
(.24)\end{array}$ & $4.19^{d}$ \\
\hline WC/S & $\begin{array}{c}.59 \\
(3.49)\end{array}$ & $\begin{array}{l}.11 \\
(.34)\end{array}$ & $\begin{array}{l}.13 \\
(.30)\end{array}$ & $\begin{array}{l}.12 \\
(.50)\end{array}$ & $5.46^{\mathrm{d}}$ \\
\hline $\mathrm{RE} / \mathrm{TA}$ & $\begin{array}{l}.15 \\
(.75)\end{array}$ & 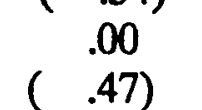 & $\begin{array}{l}.07 \\
(.48)\end{array}$ & $\begin{array}{l}.132 \\
(.35)\end{array}$ & $2.76^{e}$ \\
\hline WC/TA ${ }^{c}$ & $\begin{array}{l}.29 \\
(\quad .25)\end{array}$ & $\begin{array}{l}.16 \\
(.29)\end{array}$ & $\begin{array}{l}.20 \\
(.32)\end{array}$ & $\begin{array}{l}.24 \\
(\quad .24)\end{array}$ & $4.00^{\mathrm{d}}$ \\
\hline $\mathrm{CL} / \mathrm{CA}^{\mathrm{c}}$ & $\begin{array}{l}.56 \\
(.57)\end{array}$ & $\begin{array}{c}.87 \\
(1.03)\end{array}$ & $\begin{array}{c}1.67 \\
\left(\begin{array}{c}.92 \\
)\end{array}\right)\end{array}$ & $\begin{array}{c}.78 \\
(1.83)\end{array}$ & $-2.74^{e}$ \\
\hline OENEG ${ }^{c}$ & $\begin{array}{l}.02 \\
(.14)\end{array}$ & $\begin{array}{l}.15 \\
(.36)\end{array}$ & $\begin{array}{l}.05 \\
(.21)\end{array}$ & $\begin{array}{l}.04 \\
(.19)\end{array}$ & $-3.34^{d}$ \\
\hline FU/TLC & $\begin{array}{l}.23 \\
(\quad .83)\end{array}$ & $\begin{array}{l}.07 \\
(.38)\end{array}$ & $\begin{array}{l}.11 \\
(.27)\end{array}$ & $\begin{array}{l}.11 \\
(\quad .36)\end{array}$ & $3.59^{d}$ \\
\hline
\end{tabular}




\begin{tabular}{|c|c|c|c|c|c|}
\hline & \multirow[b]{2}{*}{$\begin{array}{l}\text { Nonbankrupt } \\
\text { Firms }\end{array}$} & \multicolumn{3}{|c|}{ Bankrupt Firms } & \\
\hline & & $\begin{array}{l}\text { Model } \\
\text { One }\end{array}$ & $\begin{array}{c}\text { Model } \\
\text { Two }\end{array}$ & $\begin{array}{l}\text { Model } \\
\text { Three }\end{array}$ & \\
\hline Variable & $\begin{array}{l}\text { Mean } \\
\text { (SD) }\end{array}$ & $\begin{array}{l}\text { Mean } \\
\text { (SD) }\end{array}$ & $\begin{array}{l}\text { Mean } \\
\text { (SD) }\end{array}$ & $\begin{array}{l}\text { Mean } \\
\text { (SD) }\end{array}$ & $t$-test \\
\hline $\mathrm{INTWO}^{\mathrm{c}}$ & $\begin{array}{l}.08 \\
(.27)\end{array}$ & $\begin{array}{l}.36 \\
(.48)\end{array}$ & $\begin{array}{l}.26 \\
(.44)\end{array}$ & $\begin{array}{l}.12 \\
(.32)\end{array}$ & $-5.38^{d}$ \\
\hline $\mathrm{CHIN}^{\mathrm{e}}$ & $\begin{array}{l}.12 \\
(.55)\end{array}$ & $\left(\begin{array}{c}-.15 \\
.56)\end{array}\right.$ & $\left(\begin{array}{c}-.02 \\
.61)\end{array}\right.$ & $\begin{array}{l}.08 \\
(.77)\end{array}$ & $4.32^{d}$ \\
\hline
\end{tabular}

$\overline{{ }^{2} \text { CBR variables are described in Table 4; logit variables are described in Table } 5 .}$

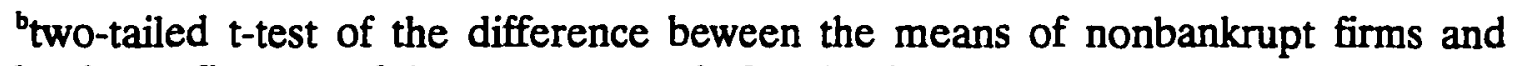
bankrupt firms, model one, one year before bankruptcy

Togit variables

dsignificant at alpha $=.001$

${ }^{\mathrm{e}}$ significant at alpha $=.01$

significant at alpha $=.10$

\section{CBR Analysis}

In order to create the CBR cluster trees, three case libraries were established. Model one, model two, and model three are case libraries consisting of the 2,000 nonbankrupt firms' 25 ratios (approximately 50,000 ratios), plus the 85 bankrupt firms' 25 ratios (approximately 2,125 ratios) for one year, two years, and three years, respectively, before bankruptcy. This composition of bankrupt to nonbankrupt firms is consistent with Ohlson's (1980) ratio of bankrupt to nonbankrupt firms. Thus, the probability of bankruptcy in the sample is .041 . 


\section{Verification Procedures}

Two procedures suggested by O'Leary (1993) were used to verify the completeness of the case libraries. The results of these two procedures are presented in Tables 9 and 10 . Table 9 describes the distribution of missing attributes across CBR cases. The vast majority of cases in the library are not missing any attributes. For example, $86.95 \%$ of nonbankrupt firms have data for all attributes. Similarly, models one, two, and three, which represent one year, two years, and three years prior to bankruptcy, have $82.35 \%, 89.41 \%$, and $82.35 \%$ of cases with complete data. Only one bankrupt firm (from model three) has greater than $44 \%$ of attributes missing. The CBR models were run both with that case and without that case, with no difference in results. Based on the completeness of the case library, no cases were dropped from the sample.

\section{TABLE 9}

VERIFICATION OF THE CBR COMPLETENESS DISTRIBUTION OF MISSING ATTRIBUTES ACROSS CBR CASES

\begin{tabular}{|c|c|c|c|c|}
\hline \multirow{3}{*}{$\begin{array}{l}\text { Percent of } \\
\text { Attributes } \\
\text { Missing }\end{array}$} & \multicolumn{4}{|c|}{ Percent of Cases Missing Antributes: } \\
\hline & \multirow[b]{2}{*}{$\begin{array}{l}\text { Nonbankrupt } \\
\text { Firms }(n=2,000)\end{array}$} & \multicolumn{3}{|c|}{ Bankrupt Firms $(n=85)$} \\
\hline & & $\begin{array}{l}\text { Model } \\
\text { One }\end{array}$ & $\begin{array}{l}\text { Model } \\
\text { Two }\end{array}$ & $\begin{array}{l}\text { Model } \\
\text { Three }\end{array}$ \\
\hline$\overline{0}$ & 86.95 & 82.35 & 89.41 & 82.35 \\
\hline$<10$ & 2.65 & 11.76 & 3.53 & 3.53 \\
\hline $10 \leq n \leq 20$ & 7.50 & 5.88 & 4.71 & 7.06 \\
\hline $20 \leq n \leq 30$ & 1.20 & & 2.35 & \\
\hline $30 \leq n \leq 40$ & .35 & & & \\
\hline$>44$ & & & & 1.18 \\
\hline
\end{tabular}


A second completeness test were performed to describe the distribution of nil slots per CBR attribute. The purpose of this test was to discover any problematic attribute that may have had to be removed from the case library if sufficient data across firms were not available. The results of this completeness test are reported in Table 10. Data may be missing for a given variable for two reasons: either the data are not available from Compustat, or a ratio is truncated as an outlier. The major cause of missing data, however, is unavailability of a given data item for a firm on Compustat. From examination of Table 10, there appears to be no problematic attribute. The variables with the highest missing percentages are COGS/I (cost of goods sold/inventory), RE/I (retained earnings/inventory), and I/S (inventory/sales). Missing data for these variables is due to missing inventory data for some Compustat firms. As the percent of missing data is low, no variables were dropped from the sample.

\section{Holdout Samples}

The current study used two types of holdout samples. A traditionally-used $10 \%$ in-period holdout sample was used to cross-validate both the CBR and the logit models after their initial construction. The firm observations from 1990-1994 were used in both the CBR and logit models as an out-of-period holdout sample to validate the models with data from outside the time period used to construct the models. Data from the holdout samples were not used in construction of either the CBR models or the logit models. Because there is insufficient data from 1975 to estimate one variable of the logit models, 100 nonbankrupt firms from 1975 were 
TABLE 10

\section{VERIFICATION OF THE CBR COMPLETENESS DISTRIBUTION OF NIL SLOTS PER CBR ATTRIBUTE}

\begin{tabular}{|c|c|c|c|c|}
\hline \multirow[b]{3}{*}{ Attribute } & \multicolumn{4}{|c|}{ Percent of Cases With Missing Attribute: } \\
\hline & \multirow[b]{2}{*}{$\begin{array}{l}\text { Nonbankrupt } \\
\text { Firms }\end{array}$} & \multicolumn{3}{|c|}{ Bankrupt Firms } \\
\hline & & $\begin{array}{l}\text { Model } \\
\text { One }\end{array}$ & $\begin{array}{l}\text { Model } \\
\text { Two }\end{array}$ & $\begin{array}{l}\text { Model } \\
\text { Three }\end{array}$ \\
\hline$\overline{\text { SIZE }}$ & .1 & & & \\
\hline NI/S & .5 & & & \\
\hline $\begin{array}{l}\text { NI/TA } \\
\text { NI/NW }\end{array}$ & & & & \\
\hline $\begin{array}{l}\text { NI/NW } \\
\text { EBIT/TA }\end{array}$ & .4 & 1.2 & & 2.0 \\
\hline S/TA & & 1.2 & & \\
\hline CA/TA & 2.1 & 2.4 & 2.0 & 4.0 \\
\hline QA/TA & .7 & & & 1.0 \\
\hline S/NW & .8 & 2.4 & 1.0 & 2.0 \\
\hline CA/S & 2.4 & 3.5 & 2.0 & 4.0 \\
\hline I/S & 5.7 & 3.5 & 2.0 & 4.0 \\
\hline COGS/I & 6.2 & 4.7 & 2.0 & 5.0 \\
\hline TL/NW & .5 & & 1.0 & 2.0 \\
\hline TL/TA & .1 & & & \\
\hline QA/S & 1.1 & 1.2 & & 1.0 \\
\hline $\mathrm{RE} / \mathrm{I}$ & 7.1 & 1.2 & 4.0 & 5.0 \\
\hline $\mathrm{CA} / \mathrm{CL}$ & 2.2 & 4.7 & 4.0 & 5.0 \\
\hline QA/CL & 2.5 & 2.4 & 1.0 & 1.0 \\
\hline CLTTA & 1.7 & 2.4 & 1.0 & 1.0 \\
\hline C/TA & 2.7 & 2.4 & 2.0 & 1.0 \\
\hline $\mathrm{C} / \mathrm{CL}$ & 4.5 & 5.9 & 4.0 & 1.0 \\
\hline $\mathbf{S} / \mathbf{C}$ & 3.5 & 7.1 & 5.0 & 1.0 \\
\hline WC/TA & 1.6 & & & 1.0 \\
\hline WC/S & 1.8 & 1.2 & 1.0 & 1.0 \\
\hline RE/TA & 1.5 & 1.2 & & 1.0 \\
\hline
\end{tabular}

dropped from the sample for the logit models only. Table 11 summarizes the composition of the CBR and logit holdout samples. 
TABLE 11

HOLDOUT SAMPLES

\begin{tabular}{|c|c|c|c|c|}
\hline & $\overline{\mathrm{BR}^{2}}$ & $\mathrm{NBR}^{\mathrm{b}}$ & Total & Years \\
\hline \multicolumn{5}{|l|}{ CBR: } \\
\hline $\begin{array}{l}\text { Total Sample } \\
\text { Less: Out-of-Period } \\
\text { Sample }\end{array}$ & $\begin{array}{c}85 \\
(14)\end{array}$ & $\begin{array}{c}2,000 \\
(500)\end{array}$ & $\begin{array}{c}2,085 \\
(514)\end{array}$ & $\begin{array}{l}1975-1994 \\
1990-1994\end{array}$ \\
\hline \multirow{2}{*}{$\begin{array}{l}\text { Less: In-Period } \\
\text { Sample }\end{array}$} & (7) & $(150)$ & (157) & $1975-1989$ \\
\hline & $\underline{64}$ & 1,350 & $\underline{1,414}$ & $1975-1989$ \\
\hline $\begin{array}{l}\text { Total Sample } \\
\text { Less: Out-of-Period } \\
\text { Sample }\end{array}$ & $\begin{array}{c}85 \\
(14)\end{array}$ & $\begin{array}{c}1,900 \\
(500)\end{array}$ & $\begin{array}{c}1,985 \\
(514)\end{array}$ & $\begin{array}{l}1976-1994 \\
1990-1994\end{array}$ \\
\hline \multirow[t]{2}{*}{$\begin{array}{l}\text { Less: In-Period } \\
\text { Sample }\end{array}$} & (8) & $(140)$ & $(148)$ & 1976-1989 \\
\hline & $\underline{63}$ & $\underline{1,260}$ & $\underline{1,323}$ & 1976-1989 \\
\hline
\end{tabular}

\section{Tests of Hypothesis One}

To test hypothesis one, CBR decision trees were created with 1,500 nonbankrupt firms from 1975-1989 and 71 bankrupt firms from the same time period. The remaining 500 nonbankrupt firms and 14 bankrupt firms from 19901994 were used to test the predictive ability of the decision trees on an out-ofperiod sample. For each of the three case libraries, ten decision trees were created using ReMind's "view" option. Ten percent of the 1,571 cases were designated as holdout cases for the purpose of testing the accuracy of the decision tree. Thus, each decision tree was created with 1,414 firms (1,350 nonbankrupt and 64 bankrupt), with the remaining 157 firms (150 nonbankrupt and 7 bankrupt, on 
average) used to test the accuracy of the decision tree. Because decision trees can vary radically with a change in composition of the case library and test samples, ten mutually exclusive views (decision trees) were created for each model. Each decision tree was tested using the 157 firms held out for that view. ReMind took an average of 75 minutes to cluster each of the 30 decision trees, with an average of 85 splits in each tree. ${ }^{43}$

Tables 12,13 , and 14 report the results of testing the predictive accuracy of the 30 decision trees (ten for each of models one, two, and three) with their respective 157 holdout firms. The contingency tables show the average over ten decision trees of correct and incorrect classifications by the CBR. The type II error rate (which measures the probability of classifying a nonbankrupt firm as bankrupt) is only .0479 , which indicates an average accuracy of .9521 for classifying a nonbankrupt firm accurately. The type I error rate (which measures the probability of classifying a bankrupt firm as nonbankrupt) is quite high at .727 . That is, average accuracy across the ten decision trees is .273. If the costs of type I and type II errors were equal, CBR would perhaps have some validity as a predictor of which firms would not go bankrupt. However, these costs are not equal, as pointed out by Altman, Haldeman, and Narayanan $(1977,44)$, who assess

\footnotetext{
${ }^{43}$ Pruning a decision tree usually is recommended to increase the predictive accuracy by reducing noise. ReMind builds in the capability to prune by the userspecified parameter, "minimum number of cases to split." The current study explores various pruning points in the tree for each CBR model, including zero, two, five, ten, and twenty. The greatest predictive accuracy almost universally occurs when the minimum number of cases to split is set at two. This mechanism is used to prune the CBR trees.
} 
the costs as .70 and .02 for type I and type II error, respectively. The real value of CBR would be if it could predict which firms would go bankrupt, and this goal was not accomplished. Thus, the null hypothesis for model one is not rejected in favor of the alternative hypothesis that CBR is useful in predicting bankruptcy.

Table 13 reports the results of the CBR cluster tree analysis for model two, two years before bankruptcy. The probability of classifying bankrupt firms as nonbankrupt (type I error) is high at .829 , while the probability of classifying a nonbankrupt firm as bankrupt (type II error) drops to .024 . The average type I and type II error rate is .4265 . The null hypothesis for model two is not rejected, and it is concluded that the overall CBR model is not useful for predicting bankruptcy.

TABLE 12

RESULTS OF CBR CLUSTER TREE ANALYSIS: MODEL ONE HOLDOUT SAMPLE OF 157 FIRMS FROM 1975-1989

AVERAGED OVER $V=10$ SEPARATE VIEWS

\begin{tabular}{lcccc}
\hline & \multicolumn{3}{c}{ Actual Firm Status } \\
\cline { 3 - 5 } Predicted & $\mathrm{B}^{\mathrm{a}}$ & $\mathrm{NB}^{\mathrm{b}}$ & Totals \\
by CBR & 1.80 & 7.20 & 9.00 \\
& $\mathrm{NB}^{\mathrm{b}}$ & $\frac{4.80}{6.60}$ & $\frac{143.20}{150.40}$ & $\frac{148.00}{157.00}$ \\
& & & & \\
Type I error & & & & \\
Type II error & & .7270 & & \\
Average error & & .0479 & & \\
\hline
\end{tabular}

bankrupt firms

bonbankrupt firms 
TABLE 13

RESULTS OF CBR CLUSTER TREE ANALYSIS: MODEL TWO HOLDOUT SAMPLE OF 157 FIRMS FROM 1975-1989

AVERAGED OVER V=10 SEPARATE VIEWS

\begin{tabular}{lrrrr}
\hline \multirow{2}{*}{ p539 } & \multicolumn{3}{c}{ Actual Firm Status } \\
\cline { 2 - 5 } Predicted & $\mathrm{B}^{\mathrm{a}}$ & 1.17 & $\mathrm{NB}^{\mathrm{a}}$ & Totals \\
by CBR & $\mathrm{NB}^{\mathrm{b}}$ & $\frac{5.67}{6.84}$ & $\frac{146.50}{150.17}$ & $\frac{152.17}{157.01}$ \\
& & & & \\
& & & \\
Type I error & .8290 & & \\
Type II error & .0240 & & \\
Average error & .4265 & & \\
& & & & \\
abankrupt firms & & & \\
bnonbankrupt firms & & &
\end{tabular}

Table 14 reports the results of the CBR cluster tree analysis for model three, three years before bankruptcy. Again, the results were averaged across ten mutually exclusive decision trees. The type I error rate is .903 , while type II error rate is .052. The average type I and type II error rate is .4775 . These error rates indicate that the CBR model is not useful in predicting bankruptcy.

The accuracy of the CBR models was also tested using 514 firms (500 nonbankrupt and 14 bankrupt) from 1990-1994. This test determines the accuracy of the CBR on a set of firms from a time period in the future. High predictive accuracies obtained by other models, including logit, have been found to decline when tested on data from outside the time period from which the model was 
created. The 514 firms were input into each of the 30 CBR decision trees (ten trees each for

TABLE 14

RESULTS OF CBR CLUSTER TREE ANALYSIS: MODEL THREE HOLDOUT SAMPLE OF 157 FIRMS FROM 1975-1989

AVERAGED OVER V=10 SEPARATE VIEWS

\begin{tabular}{|c|c|c|c|c|}
\hline \multirow[b]{2}{*}{$\begin{array}{l}\text { Predicted } \\
\text { by CBR }\end{array}$} & \multirow[b]{2}{*}{$\begin{array}{r}\mathrm{B}^{\mathrm{a}} \\
\mathrm{NB}^{\mathrm{b}}\end{array}$} & \multicolumn{3}{|c|}{ Actual Firm Status } \\
\hline & & $\begin{array}{r}\mathrm{B}^{\mathrm{a}} \\
.70 \\
6.50 \\
7.20\end{array}$ & $\begin{array}{r}\mathrm{NB}^{\mathrm{b}} \\
7.80 \\
142.10 \\
149.90\end{array}$ & $\begin{array}{r}\text { Totals } \\
8.50 \\
148.60 \\
157.10\end{array}$ \\
\hline $\begin{array}{l}\text { Type I error } \\
\text { Type II error } \\
\text { Average error }\end{array}$ & & $\begin{array}{l}.9030 \\
.0520 \\
.4775\end{array}$ & & \\
\hline
\end{tabular}

bankrupt firms

bonbankrupt firms

models one through three created using the data from 1975-1989). Results of these tests are described in Tables 15, 16, and 17.

Table 15 shows the results of model one using the 514 firms from 1990-1994. The 514 firms were input into each of the ten decision trees created in model one. The accuracy rates were then averaged. Interestingly, the out-of-period sample appears to be slightly more accurate than the in-period test sample. The probability of classifying bankrupt firms as nonbankrupt (type I error) is .729 , while the probability of classifying nonbankrupt firms as bankrupt (type II error) is .049. The 
average of the type I and type II error rates is .389. CBR appears to be quite successful at classifying nonbankrupt firms, but unsuccessful at classifying bankrupt firms. Again, given the high cost of a type I error, the value of the CBR would be in correctly classifying bankrupt firms and not in correctly classifying nonbankrupt firms. Based on the high type I error rate, the null hypothesis for hypothesis one is not rejected, and it is concluded that the CBR model is not useful in predicting bankruptcy.

TABLE 15

RESULTS OF CBR CLUSTER TREE ANALYSIS: MODEL ONE HOLDOUT SAMPLE OF 514 FIRMS FROM 1990-1994 AVERAGED OVER $V=10$ SEPARATE VIEWS

\begin{tabular}{lrrrr}
\hline & \multicolumn{3}{c}{ Actual Firm Status } \\
\cline { 3 - 5 } & & $\mathrm{B}^{\mathrm{a}}$ & $\mathrm{NB}^{\mathrm{b}}$ & Totals \\
Predicted & $\mathrm{B}^{2}$ & 3.80 & 24.40 & 28.20 \\
by CBR & $\mathrm{NB}^{\mathrm{b}}$ & $\frac{10.20}{14.00}$ & $\frac{475.60}{500.00}$ & $\frac{485.80}{514.00}$
\end{tabular}

$\begin{array}{ll}\text { Type I error } & .7290 \\ \text { Type II error } & .0490 \\ \text { Average error } & .3890\end{array}$

bankrupt firms

nonbankrupt firms

Table 16 reports the results of the CBR cluster tree analysis for model two, two years before bankruptcy, tested with the 514 out-of-period firms from 1990 1994. The type II error rate is a low .029 , while the type I error rate rises to .893 . The average type I and type II error rate is .461 . Thus, model two does not appears to be useful for predicting bankruptcy and the null hypothesis is not rejected. 
TABLE 16

RESULTS OF CBR CLUSTER TREE ANALYSIS: MODEL TWO

HOLDOUT SAMPLE OF 514 FIRMS FROM 1990-1994

AVERAGED OVER V=10 SEPARATE VIEWS

\begin{tabular}{|c|c|c|c|c|}
\hline \multirow[b]{2}{*}{$\begin{array}{l}\text { Predicted } \\
\text { by CBR }\end{array}$} & \multirow[b]{2}{*}{$\begin{array}{r}\mathrm{B}^{\mathrm{a}} \\
\mathrm{NB}^{\mathrm{b}}\end{array}$} & \multicolumn{3}{|c|}{ Actual Firm Status } \\
\hline & & $\begin{array}{r}\mathrm{B}^{\mathrm{a}} \\
1.50 \\
\frac{12.50}{14.00}\end{array}$ & $\begin{array}{r}\mathrm{NB}^{\mathrm{b}} \\
14.33 \\
\frac{485.85}{500.18}\end{array}$ & $\begin{array}{r}\text { Totals } \\
15.83 \\
498.35 \\
514.18\end{array}$ \\
\hline $\begin{array}{l}\text { Type I error } \\
\text { Type II error } \\
\text { Average error }\end{array}$ & & $\begin{array}{l}.893 \\
.029 \\
.461\end{array}$ & & \\
\hline
\end{tabular}

Table 17 describes the results of the CBR cluster tree analysis for model three, three years before bankruptcy, tested with the 514 out-of-period firms from 1990-1994. The probability of a type I error is .90 , while the probability of a type II error is .0458 . The average type I and type II error rate is .4729 . The null hypothesis for hypothesis one is not rejected. The conclusion for the out-of-period test sample for model three is that CBR is not useful in predicting bankruptcy.

\section{Tests of Hypothesis Two: Logit Analysis}

Although the CBR models have very low predictive capability for bankrupt firms, they do successfully classify nonbankrupt firms. Thus, it is useful to compare the results of CBR with logit. Three logit models were created to compare the accuracy of CBR with the accuracy of logit. Because data were not available for 
TABLE 17

RESULTS OF CBR CLUSTER TREE ANALYSIS: MODEL THREE

HOLDOUT SAMPLE OF 514 FIRMS FROM 1990-1994

AVERAGED OVER V=10 SEPARATE VIEWS

\begin{tabular}{lrrrr}
\hline & \multicolumn{3}{c}{ Actual Firm Status } \\
\cline { 3 - 5 } & & $\mathrm{B}^{\mathrm{a}}$ & $\mathrm{NB}^{\mathrm{b}}$ & Totals \\
Predicted & $\mathrm{B}^{2}$ & 1.40 & 22.90 & 24.30 \\
by CBR & $\mathrm{NB}^{\mathrm{b}}$ & $\frac{12.60}{14.00}$ & $\frac{477.10}{500.00}$ & $\frac{489.70}{514.00}$
\end{tabular}

Type I error $\quad .9000$

Type II error $\quad .0458$

Average error $\quad .4729$

bankrupt firms

'nonbankrupt firms

creation of the variable CHIN, change in net income, for the 100 nonbankrupt firms from 1975, these 100 firms were not used in the logit analysis. Additionally, the 514 firms from 1990-1994 were used for testing the logit models with an out-of-period test sample. From the remaining 1,471 firms, 10\% were retained (140 nonbankrupt and 8 bankrupt) in order to test the logit model with a test sample from the same years as the data used to create the models. Thus, each of the three logit models created consists of nine ratios for 1,323 firms (1,260 nonbankrupt and 63 bankrupt). The ratios are as in Ohlson (1980) and are described in Table 5 in Chapter 3.

Tables 18, 19, and 20 describe the parameter estimates from fitting the logit models. These models were tested using $S A S$. Table 18 describes the results of model one, one year before bankruptcy. The overall model chi-square is 59.126 , with a p-value of .0001 . This p-value provides evidence that at least one of the 
regression coefficients for an explanatory variable is nonzero. Three variables are highly significant: SIZE, INTWO, and CHIN, with p-values of $.0008, .0023$, and .0012 , respectively. The variable OENEG is marginally significant with a p-value of .0861 . Interestingly, although the means of all these variables are significantly different in the bankrupt and nonbankrupt groups (refer to Table 8), not all of the variables are significant in the multivariate context. The signs on the significant coefficients are all as expected, with the exception of OENEG, for which no expected sign was specified (refer to Table 5 for a description of the logit variables and their expected signs). The negative coefficient on SIZE indicates that the smaller a firm is, the higher the probability of bankruptcy. The positive coefficient for the dummy variable INTWO indicates that firms that have negative net income for the last two years have a higher probability of bankruptcy. The negative coefficient on the variable CHIN indicates that smaller percent changes in net income are associated with a higher probability of bankruptcy. The positive coefficient on the dummy variable OENEG indicates a higher probability of bankruptcy for firms whose total liabilities exceed total assets.

Table 19 reports the results of the logit analysis for model two, two years before bankruptcy. The model chi-square is 41.925 , with a $p$-value of .0001 , indicating that at least one of the regression coefficients for an explanatory variable is nonzero. The variables SIZE, INTWO, and CHIN all remain highly significant with p-values of $.0004, .0025$, and .0117 , respectively. The variable OENEG is no longer significant, while the variable TL/TA is marginally significant with a p-value 
TABLE 18

PARAMETER ESTIMATES FOR LOGIT MODEL ONE

\begin{tabular}{lcrl}
\hline Variable & $\begin{array}{l}\text { Parameter } \\
\text { Estimates }\end{array}$ & Chi-Square & P-value \\
\hline Intercept & .4437 & .1335 & .7148 \\
SIZE & -.2598 & 11.1994 & .0008 \\
TL/TA & .3224 & .3342 & .5632 \\
WCTTA & -.8262 & 1.1193 & .2901 \\
CL/CA & -.3359 & 1.2194 & .2695 \\
OENEG & 1.1446 & 2.9461 & .0861 \\
NI/TA & .1509 & .0506 & .8221 \\
FU/TL & .2486 & .9529 & .3290 \\
INTWO & 1.2731 & 9.2733 & .0023 \\
CHIN & -.8559 & 10.4969 & .0012 \\
& & & \\
\hline
\end{tabular}

Model chi-square $=59.126(p=.0001)$

of .1004 . Coefficients on the significant variables are again as expected, with SIZE and CHIN having negative coefficients, and INTWO having a positive coefficient. TL/TA, which is not significant in model one, is marginally significant, and has a positive coefficient as expected. A positive coefficient on this variable is interpreted as evidence of an association between a higher debt ratio and bankruptcy.

Logit results for model three, three years before bankruptcy are reported in Table 20. Only SIZE remains significant for the model for three years before bankruptcy. The coefficient on SIZE is negative, as expected. The model chisquare is 28.988 , with a p-value of .0007 , indicating that at least one of the regression coefficients for an explanatory variable is nonzero.

Because the logit model returns a single number, a probability of bankruptcy, a cutoff point must be established to test the predictive accuracy of the models. For 
TABLE 19

PARAMETER ESTIMATES FOR LOGIT MODEL TWO

\begin{tabular}{lrrl}
\hline Variable & $\begin{array}{l}\text { Parameter } \\
\text { Estimates }\end{array}$ & Chi-Square & P-value \\
\hline Intercept & -.0890 & .0061 & .9376 \\
SIZE & -.2738 & 12.5423 & .0004 \\
TL/TA & .9979 & 2.6988 & .1004 \\
WC/TA & .1161 & .0418 & .8380 \\
CL/CA & .0614 & 1.2957 & .2550 \\
OENEG & -1.6386 & 1.7263 & .1889 \\
NITA & .7859 & .6169 & .4322 \\
FU/TL & .1328 & .3245 & .5689 \\
INTWO & 1.3275 & 9.1338 & .0025 \\
CHIN & -.6582 & 6.3614 & .0117
\end{tabular}

Model chi-square $=41.925928(p=.0001)$

TABLE 20

PARAMETER ESTIMATES FOR LOGIT MODEL THREE

\begin{tabular}{lrrl}
\hline Variable & $\begin{array}{r}\text { Parameter } \\
\text { Estimates }\end{array}$ & Chi-Square & P-value \\
\hline Intercept & .6552 & .3020 & .5827 \\
SIZE & -.3226 & 17.1909 & .0001 \\
TLTA & .9794 & 2.3177 & .1279 \\
WC/TA & .2984 & .2003 & .6545 \\
CL/CA & .2163 & 1.9538 & .1622 \\
OENEG & -1.4150 & .7562 & .3845 \\
NI/TA & -.1441 & .0622 & .8030 \\
FU/TL & -.0468 & .0783 & .7796 \\
INTWO & -.4531 & .5305 & .4664 \\
CHIN & -.2485 & 1.1119 & .2917 \\
\hline
\end{tabular}

Model chi-square $=28.988(p=.0007)$

each of the three models, a $S A S$ macro was used to search for the cutoff point that minimizes the sum of the type I and type II errors, putting equal weight of $50 \%$ on 
type I and type II errors. ${ }^{44}$ Results of these procedures are reported in Tables 21 , 22 , and 23.

Table 21 reports the results of the accuracy of the $10 \%$ holdout sample (140 nonbankrupt firms and 8 bankrupt firms) tested at various cutoff points in model one, created with 1,323 firms (1,260 nonbankrupt and 63 bankrupt). The probability cutoff points that minimize the sum of the type I and type II errors are .048 and .049 (tied). At either of these probability cutoff points, the probability of classifying a bankrupt firm as nonbankrupt (type I error) is .25 , while the probability of classifying a nonbankrupt firm as bankrupt (type II error) is .20. The average type I and type II error rate is .225 .

Table 22 reports the results of the accuracy of the $10 \%$ holdout sample (140 nonbankrupt firms and 8 bankrupt firms) tested at various cutoff points in model two, created with 1,323 firms (1,260 nonbankrupt and 63 bankrupt). The probability cutoff point that minimizes the sum of the type I and type II errors is .038 . At this probability cutoff point, the probability of classifying a bankrupt firm as nonbankrupt (type I error) is 0.0 , while the probability of classifying a nonbankrupt firm as bankrupt rate (type II error) is .4286 . The average type I and type II error rate is .2143 , slightly lower than for model one.

\footnotetext{
${ }^{44}$ Although the costs of type I and type II errors are not equal, many researchers follow this convention for simplicity. Both Ohlson (1980) and Begley, Ming, and Watts (1995) calculate cutoff points assuming equal weighting of errors. Because the objective of this study is to compare to Ohlson (1980), the current study follows this convention.
} 
TABLE 21

LOGIT MODEL ONE: ANALYSIS OF CUTOFF POINTS HOLDOUT SAMPLE OF 148 FIRMS FROM 1976-1989

\begin{tabular}{cccc}
\hline Cutoff points & Type I & Type II & Average \\
\hline 0.000 & $0.00 \%$ & $100.00 \%$ & $50.00 \%$ \\
0.010 & 0.00 & 97.14 & 48.57 \\
0.015 & 0.00 & 89.29 & 44.65 \\
0.020 & 0.00 & 76.43 & 38.22 \\
0.025 & 0.00 & 63.57 & 31.79 \\
0.030 & 12.80 & 47.86 & 30.33 \\
0.035 & 12.80 & 37.85 & 25.33 \\
0.040 & 25.00 & 32.14 & 28.57 \\
0.045 & 25.00 & 25.71 & 25.36 \\
0.046 & 25.00 & 25.00 & 25.00 \\
0.047 & 25.00 & 22.14 & 23.57 \\
$0.048^{*}$ & 25.00 & 20.00 & 22.50 \\
$0.049^{*}$ & 25.00 & 20.00 & 22.50 \\
0.050 & 37.50 & 19.29 & 28.40 \\
0.055 & 50.00 & 15.00 & 32.50 \\
0.060 & 50.00 & 12.86 & 31.43 \\
0.080 & 50.00 & 7.14 & 28.57 \\
0.100 & 63.00 & 2.14 & 32.32 \\
0.200 & 75.00 & 0.71 & 37.86 \\
0.300 & 88.00 & 0.71 & 44.11 \\
0.700 & 100.00 & 0.00 & 50.00 \\
1.000 & 100.00 & 0.00 & 50.00 \\
& & &
\end{tabular}

F.048 and .049 are the probability cutoff points that minimize the sum of the type I and type II errors.

Table 23 reports the results of the accuracy of the $10 \%$ holdout sample (140 nonbankrupt firms and 8 bankrupt firms) tested at various cutoff points in model three, created with 1,323 firms (1,260 nonbankrupt and 63 bankrupt). The probability cutoff point that minimizes the sum of the type I and type II errors is .06. At this probability cutoff point, the probability of classifying a bankrupt firm as nonbankrupt (type I error) remains .25 , while the probability of classifying a nonbankrupt firm as bankrupt (type II error) drops to .1786 . The average type I and type II error rate is .2143 , lower than for model one and equal to model two. 
TABLE 22

LOGIT MODEL TWO: ANALYSIS OF CUTOFF POINTS HOLDOUT SAMPLE OF 148 FIRMS FROM 1976-1989

\begin{tabular}{lccc}
\hline Cutoff points & Type I & Type II & Average \\
\hline 0.000 & $0.00 \%$ & $100.00 \%$ & $50.00 \%$ \\
0.010 & 0.00 & 97.86 & 48.93 \\
0.020 & 0.00 & 80.71 & 40.36 \\
0.025 & 0.00 & 70.00 & 35.00 \\
0.030 & 0.00 & 57.14 & 28.57 \\
0.035 & 0.00 & 47.14 & 23.57 \\
0.036 & 0.00 & 46.43 & 23.21 \\
0.037 & 0.00 & 45.00 & 22.50 \\
$0.038^{*}$ & 0.00 & 42.86 & 21.43 \\
0.039 & 12.50 & 42.14 & 27.32 \\
0.040 & 13.00 & 40.00 & 26.25 \\
0.050 & 25.00 & 23.57 & 24.29 \\
0.060 & 63.00 & 14.29 & 38.40 \\
0.100 & 88.00 & 3.57 & 45.54 \\
0.200 & 88.00 & 0.00 & 43.75 \\
0.300 & 100.00 & 0.00 & 50.00 \\
1.000 & 100.00 & 0.00 & 50.00
\end{tabular}

${ }^{*} .038$ is the probability cutoff point that minimizes the sum of the type I and type II errors.

To test the predictive accuracy of the logit models for a sample of firms from outside the time period from which the model is created, 514 firms (500 nonbankrupt and 14 bankrupt) from 1990-1994 were input into the previously created logit models. Predictive accuracy was determined using the cutoff points from the previously fitted logit models. The results are presented in Tables 24, 25, and 26. 
TABLE 23

LOGIT MODEL THREE: ANALYSIS OF CUTOFF POINTS HOLDOUT SAMPLE OF 148 FIRMS FROM 1976-1989

\begin{tabular}{lccl}
\hline Cutoff points & Type I & Type II & Average \\
\hline 0.000 & $0.00 \%$ & $100.00 \%$ & $50.00 \%$ \\
0.010 & 0.00 & 99.29 & 49.64 \\
0.020 & 0.00 & 81.43 & 40.72 \\
0.025 & 0.00 & 70.71 & 35.36 \\
0.030 & 0.00 & 63.57 & 31.79 \\
0.035 & 12.50 & 53.57 & 33.04 \\
0.040 & 25.00 & 42.14 & 33.57 \\
0.045 & 25.00 & 32.14 & 28.57 \\
0.050 & 25.00 & 26.43 & 25.72 \\
0.055 & 25.00 & 23.57 & 24.29 \\
0.056 & 25.00 & 22.14 & 23.57 \\
0.057 & 25.00 & 20.71 & 22.86 \\
0.058 & 25.00 & 20.00 & 22.50 \\
0.059 & 25.00 & 19.29 & 22.15 \\
$0.060 *$ & 25.00 & 17.86 & 21.43 \\
0.061 & 37.50 & 15.71 & 26.61 \\
0.062 & 37.50 & 15.71 & 26.61 \\
0.070 & 75.00 & 10.71 & 42.86 \\
0.080 & 88.00 & 7.14 & 47.32 \\
0.100 & 88.00 & 2.86 & 45.18 \\
0.200 & 100.00 & 1.43 & 50.72 \\
0.300 & 100.00 & 0.00 & 50.00 \\
1.000 & 100.00 & 0.00 & 50.00 \\
& & & \\
\hline
\end{tabular}

*.06 is the cutoff point that minimizes the sum of the type I and type II errors.

Table 24 reveals that at the previously identified cutoff points of .048 and .049 for model one, type I errors are .0714 and type II errors are .298 and .292 . The average of type I and type II errors is .1847 and .1817. There is a considerably lower type I error rate, but a higher type II error rate than model one tested with the in-period holdout sample. The average type I and type II error rate is lower 
TABLE 24

LOGIT MODEL ONE: ANALYSIS OF CUTOFF POINTS HOLDOUT SAMPLE OF 514 FIRMS FROM 1990-1994

\begin{tabular}{|c|c|c|c|}
\hline Cutoff points & Type I & Type II & Average \\
\hline 0.000 & $0.00 \%$ & $99.80 \%$ & $49.90 \%$ \\
\hline 0.010 & 0.00 & 96.00 & 48.00 \\
\hline 0.020 & 0.00 & 75.20 & 37.60 \\
\hline 0.025 & 0.00 & 64.00 & 32.00 \\
\hline 0.030 & 0.00 & 54.60 & 27.30 \\
\hline 0.035 & 7.14 & 46.00 & 26.57 \\
\hline 0.040 & 7.00 & 38.20 & 22.67 \\
\hline 0.045 & 7.14 & 33.20 & 20.17 \\
\hline $0.048^{*}$ & 7.14 & 29.80 & 18.47 \\
\hline $0.049^{*}$ & 7.14 & 29.20 & 18.17 \\
\hline 0.050 & 7.14 & 28.80 & 17.97 \\
\hline 0.080 & 14.29 & 16.20 & 15.25 \\
\hline 0.081 & 14.29 & 15.60 & 14.95 \\
\hline 0.082 & 14.29 & 15.20 & 14.75 \\
\hline 0.083 & 14.29 & 14.40 & 14.35 \\
\hline $0.084^{* *}$ & 14.29 & 14.20 & 14.25 \\
\hline $0.085^{* *}$ & 14.29 & 14.20 & 14.25 \\
\hline 0.090 & 28.57 & 12.60 & 20.59 \\
\hline 0.100 & 29.00 & 10.40 & 19.49 \\
\hline 0.200 & 64.00 & 3.00 & 33.65 \\
\hline 0.400 & 79.00 & 0.40 & 39.49 \\
\hline 0.500 & 93.00 & 0.59 & 46.73 \\
\hline 0.600 & 100.00 & 0.20 & 50.10 \\
\hline 1.000 & 100.00 & 0.00 & 50.00 \\
\hline
\end{tabular}

".048 and .049 are the probability cutoff points that minimize the sum of the type I and type II errors from the fitted model using a holdout sample of $n=148$ firms from 1976-1989 (See Table 21).

** .084 and .085 are the probability cutoff points that minimize the sum of the type I and type II errors from the fitted model using a holdout sample of $n=514$ firms from 1990-1994.

than the .225 of the original model. The cutoff points that minimize the sum of the type I and type II error for this sample are .084 and .085 (tied), for an average of 
type I and type II errors of .1425 , indicating an even higher predictive accuracy for the out-of-period sample compared with the in-period holdout sample from the 1976-1989 time period.

Table 25 presents the results of the logit analysis for model two using an out-of-period holdout sample of 514 firms from 1990-1994. Using the previously established cutoff point of .038 , type I errors are .2143 , while type II errors are .428 . The average of type I and type II errors is .3212 , higher than for model one. The cutoff point that minimizes the sum of the type I and type II error for this sample is .08. At that cutoff point, type I errors are .29 and type II errors are .12, with an average type I and type II error of .2029.

TABLE 25

LOGIT MODEL TWO: ANALYSIS OF CUTOFF POINTS HOLDOUT SAMPLE OF 514 FIRMS FROM 1990-1994

\begin{tabular}{cccc}
\hline Cutoff points & Type I & Type II & Average \\
\hline 0.000 & $0.00 \%$ & $100.00 \%$ & $50.00 \%$ \\
0.020 & 0.00 & 80.80 & 40.40 \\
$0.038^{*}$ & 21.43 & 42.80 & 32.12 \\
0.040 & 21.43 & 40.20 & 30.82 \\
0.050 & 21.43 & 27.40 & 24.42 \\
0.060 & 29.00 & 20.80 & 24.69 \\
$0.080^{* *}$ & 29.00 & 12.00 & 20.29 \\
0.085 & 50.00 & 10.80 & 30.40 \\
0.090 & 50.00 & 9.80 & 29.90 \\
0.100 & 50.00 & 7.40 & 28.70 \\
0.200 & 93.00 & 1.20 & 47.03 \\
0.300 & 100.00 & 0.20 & 50.10 \\
1.000 & 100.00 & 0.00 & 50.00
\end{tabular}

.038 is the probability cutoff point that minimizes the sum of the type I and type II errors from the fitted model using a holdout sample of $n=148$ firms from 1976-1989 (See Table 22).

**.08 is the probability cutoff point that minimizes the sum of the type I and type Il errors from the fitted model using a holdout sample of $n=514$ firms from 1990-1994. 
Table 26 presents the results of the logit analysis for model three using an out-of-period holdout sample of 514 firms from 1990-1994. Using the previously established cutoff point of .06, type I errors are .71, while type II errors are .1440 . The average of type I and type II errors is .4292 , higher than for either model one or model two. The cutoff point that minimizes the sum of the type I and type II error for this sample is .04. At that cutoff point, type I errors are .14 and type II errors are .402 , and an average type I and type II error of .2725 .

TABLE 26

LOGIT MODEL THREE: ANALYSIS OF CUTOFF POINTS HOLDOUT SAMPLE OF 514 FIRMS FROM 1990-1994

\begin{tabular}{lccc}
\hline Cutoff points & Type I & Type II & Average \\
\hline 0.000 & $0.00 \%$ & $100.00 \%$ & $50.00 \%$ \\
0.010 & 0.00 & 97.20 & 48.60 \\
0.020 & 0.00 & 83.20 & 41.60 \\
0.025 & 0.00 & 74.40 & 37.20 \\
0.030 & 14.29 & 62.20 & 38.25 \\
0.035 & 14.29 & 51.00 & 32.65 \\
0.039 & 14.29 & 42.20 & 28.25 \\
$0.040^{* *}$ & 14.00 & 40.20 & 27.25 \\
0.045 & 57.14 & 29.80 & 43.47 \\
0.050 & 57.14 & 24.00 & 40.57 \\
$0.060^{*}$ & 71.00 & 14.40 & 42.92 \\
0.080 & 79.00 & 6.80 & 42.69 \\
0.100 & 86.00 & 2.60 & 44.16 \\
0.200 & 100.00 & 0.00 & 50.00 \\
1.000 & 100.00 & 0.00 & 50.00
\end{tabular}

*.06 is the probability cutoff point that minimizes the sum of the type I and type II errors from the fitted model using a holdout sample of $n=148$ firms from 1976-1989 (See Table 23).

**.04 is the probability cutoff point that minimizes the sum of the type I and type II errors from the fitted model using a holdout sample of $n=514$ firms from 1990 1994. 


\section{Comparison of CBR Performance with Logit Performance}

Hypothesis two is designed to compare the predictive accuracy of CBR with the accuracy of logit. In order to test this hypothesis, type I and type II error rates for each of the three models were compiled and compared. Table 27 provides the type I and type II error rates for both in period and out-of-period test samples. Chi-square statistics are provided with associated p-values. From examination of Table 27, it is apparent that the logit models outperform the CBR models in every instance. Thus, hypothesis two that there is no difference between CBR and logit is rejected, although the alternative hypothesis that CBR would outperform logit is not supported.

\section{Additional Analysis}

Due to the low predictive ability of the CBR models, two additional exploratory analyses were performed. First, it is useful to compare a CBR model comprised of the identical data from Ohlson (1980) with the logit models in this study. This comparison ensures that bias has not been introduced into the results by an experimental confound. A new CBR is created for model one, one year before bankruptcy, using only the nine ratios used in the logit models. The CBR model achieves an average predictive accuracy of $15.6 \%$, less than the original CBR model.

A second analysis was performed to explore the possible effects of multicollinearity between the 25 predictor variables used in the original CBR models. Pearson correlation coefficients were computed in a $25 \times 25$ matrix. 
TABLE 27

COMPARISON OF TYPE I AND TYPE II ERRORS RATES BETWEEN CBR MODEL AND LOGIT MODEL

\begin{tabular}{|c|c|c|c|c|c|}
\hline & & Type I & Type II & Average & $\begin{array}{r}\text { Chi-Square } \\
\text { (p-value) }\end{array}$ \\
\hline Model $1^{*}$ & $\begin{array}{l}\text { CBR } \\
\text { Logit }\end{array}$ & $\begin{array}{l}.727 \\
.250\end{array}$ & $\begin{array}{l}.0479 \\
.2000\end{array}$ & $\begin{array}{l}.3875 \\
.2250\end{array}$ & $\begin{array}{l}25.82 \\
(p<.001)\end{array}$ \\
\hline Model 2* & $\begin{array}{l}\text { CBR } \\
\text { Logit }\end{array}$ & $\begin{array}{l}.829 \\
.000\end{array}$ & $\begin{array}{l}.0240 \\
.4286\end{array}$ & $\begin{array}{l}.4265 \\
.2143\end{array}$ & $\begin{array}{c}117.95 \\
(p<.001)\end{array}$ \\
\hline Model $3^{*}$ & $\begin{array}{l}\text { CBR } \\
\text { Logit }\end{array}$ & $\begin{array}{l}.9030 \\
.2500\end{array}$ & $\begin{array}{l}.0520 \\
.1786\end{array}$ & $\begin{array}{l}.4775 \\
.2143\end{array}$ & $\begin{array}{l}27.95 \\
(p<.001)\end{array}$ \\
\hline Model $1^{* *}$ & $\begin{array}{l}\text { CBR } \\
\text { Logit }\end{array}$ & $\begin{array}{l}.7290 \\
.0714\end{array}$ & $\begin{array}{l}.0490 \\
.2920\end{array}$ & $\begin{array}{l}.3890 \\
.1817\end{array}$ & $\begin{array}{l}64.84 \\
(p<.001)\end{array}$ \\
\hline Model 2** & $\begin{array}{l}\text { CBR } \\
\text { Logit }\end{array}$ & $\begin{array}{l}.8930 \\
.2143\end{array}$ & $\begin{array}{l}.0290 \\
.4280\end{array}$ & $\begin{array}{l}.4610 \\
.3212\end{array}$ & $\begin{array}{l}73.79 \\
(p<.001)\end{array}$ \\
\hline Model 3** & $\begin{array}{l}\text { CBR } \\
\text { Logit }\end{array}$ & $\begin{array}{l}.9000 \\
.7100\end{array}$ & $\begin{array}{l}.0458 \\
.1440\end{array}$ & $\begin{array}{l}.4729 \\
.4292\end{array}$ & $\begin{array}{l}6.87 \\
(p<.01)\end{array}$ \\
\hline
\end{tabular}

"model validated with 10\% holdout sample from 1975-1989 (1976-1989 for logit models)

${ }^{* *}$ model validated with out-of-period test sample, 514 firms from 1990-1994

Variables with coefficients greater than $50 \%$ had one of the variables eliminated.

This analysis results in 11 ratios that are minimally correlated (less than 50\%).

Data for these 11 ratios were input into a new CBR for model one. Average 
predictive accuracy is $14.29 \%$. Thus, the current results provide no evidence that a reduced set of predictor variables yield higher predictive accuracy.

\section{$\underline{\text { Summary }}$}

This chapter compares the results of the CBR and logit analyses. Univariate tests of the CBR variables and logit variables are presented. The sample selection procedures are described and the predictive accuracy of the CBR decision trees is compared with the predictive accuracy of the logit models. Chapter 5 provides an interpretation and summary of these results, along with implications of the findings and suggestions for future research. 


\section{CHAPTER 5}

\section{SUMMARY AND CONCLUSIONS}

Chapter 4 presents the results of the empirical tests for this study. This chapter summarizes the study and presents a discussion of the implications of the findings of this research. Limitations of the study are discussed, and the chapter concludes with suggestions for future research.

\section{Summary of Study and Implications}

Two research questions are investigated in the current study. The first research question asks whether or not the artificial intelligence method of CBR can be used successfully to predict corporate bankruptcy. The second research question asks whether CBR is more accurate than the benchmark model, Ohlson's (1980) nine-factor logit model. There are two contributions of this study. First, this study represents an early attempt to demonstrate the design and construction of a CBR bankruptcy prediction system. Through this research, accounting researchers can become aware of CBR and consider its use in future projects. Second, the study adds to the bankruptcy modeling literature in determining the predictive accuracy of a CBR system as compared to Ohlson's (1980) logit model of bankruptcy prediction. 
Identification of companies that are at risk of financial failure remains a goal of many stakeholders, including auditors, investors, lenders, employees and managers. Because there is no underlying economic theory of bankruptcy, research in the area of bankruptcy prediction has been a largely trial-and-error iterative process of identifying predictor variables and searching for more accurate statistical methods.

The search for a more accurate method has led researchers from univariate analysis to multivariate analysis, such as multiple discriminant analysis and logistic regression (logit). Recently, artificial intelligence technologies such as expert systems and neural networks have become popular methods for use in bankruptcy prediction studies. However, research shows that neural networks break down with the addition of a great number of predictor variables and that networks must be retrained when adding a case. Additionally, neither neural networks nor statistical models provide an explanation or justification for their classifications.

$\mathrm{CBR}$ is an artificial intelligence technology that has become widely used in domains such as computer science, but is only just now beginning to be explored in accounting and business contexts. CBR has been described in the literature as a machine learning technique that overcomes some of the deficiencies in statistical models and neural networks, and research indicates that the predictive accuracy of CBR is high. Thus, the current study uses CBR to provide another model of bankruptcy prediction. 
In order to validate the accuracy of the CBR systems, the CBR models developed are compared to Ohlson's (1980) nine-factor logit model of bankruptcy prediction. Although Ohlson's (1980) model is the preeminent model of bankruptcy prediction, Begley, Ming, and Watts (1995) find the model's predictive accuracy declines both when it is tested with data outside the period from which the model is constructed, and when it is re-estimated with 1980 s data and tested with data from the 1980s. Therefore, in addition to cross-validating the CBR and logit models created with an in-period holdout sample, the current study cross-vaiidates both the CBR models and the logit models with an out-of-period data set as well. Investigation of the current study's research questions also reveals insight into the robustness of Ohlson's (1980) logit model with this study's data set.

The conclusion of the study is that in the context of this study, Ohlson's (1980) logit models have superior predictive accuracy than the CBR models. The most significant finding of the study is that CBR fails to measure up to the claims made in the literature. Although there is limited academic research on CBR, the current study does not support the claims in the extant literature of overall CBR superiority to other methods such as logit. In minimizing classification errors of bankrupt firms (type I errors), logit far outperforms CBR. In minimizing classification errors of nonbankrupt firms (type II errors), CBR far outperforms logit. If the costs of type I and type II errors are equal, CBR would perhaps have some validity. However, this is not the case. Altman, Haldeman, and Narayanan (1977) estimate that the cost of a type I error is approximately .70, while the cost 
of a type II error is approximately .02. The ratio of costs of type I to type II errors implies that a type I error is 35 times more costly than a type II error. Thus, if the accuracies obtained in the current study are adjusted for the cost of errors, the results here are actually worse than they appear. Based on the results of the current study, it is concluded that CBR apparently is not useful in predicting bankruptcy. Further, the accuracy rates of Ohlson's (1980) logit model are far greater than the CBR's accuracy rates.

The question is, why did CBR fail in the current research in predicting bankruptcy? There are several possibilities. One possibility is that the model is misspecified. The variables chosen in the current study were selected because they had been used in numerous other studies and across a variety of methods with fairly good success. Perhaps another set of variables would yield a higher predictive accuracy. Again, due to the lack of theory in bankruptcy modeling studies, the possibility of model misspecification would have to be explored using a trial-anderror process, much like what researchers have done for three decades.

Another possibility is that many of the variables are too highly correlated for the clustering algorithm to function properly. This possibility is explored in the study, and the results are reported in Chapter 4. However, the reduced set of 11 predictor variables may still be too highly correlated. The decision rule used is to keep variables that are less than fifty percent correlated. Sonquist, Baker, and Morgan $(1971,15)$ point out that if two predictors are highly correlated and have similar effects on the dependent variable, then the second variable usually loses 
most or all of its explanatory power and may never appear in the decision tree again. Sonquist, Baker, and Morgan $(1971,15)$ state that where a simultaneous estimation is desired, a regression model is required. This assertion also may provide insight into why the logit model performs better. Sonquist, Baker, and Morgan $(1971,14)$ state:

In regression a simultaneous estimate is made of the effects of two intercorrelated variables, each effect adjusted for the fact that those in a class on one predictor are distributed differently over classes of the other predictor.

Thus, perhaps logit handles the intercorrelations among predictor variables more efficiently, returning a more accurate model.

Still another possibility is that there is an insufficient sample size for the bankrupt firms in the current study. Although ReMind's documentation recommends at least 50 cases per outcome variable, there is evidence that the clustering algorithm in CBR, AID, may require more cases than the current study has available. Sonquist, Baker, and Morgan $(1971,3)$ state, "A word of caution to users of this program: Data sets with a thousand cases or more are necessary." It is not clear whether this statement refers to a total of one thousand cases, or a thousand cases for each outcome variable.

Two other studies, Buta (1994) and Van Zeeland (1993), discussed in Chapter 2 also use ReMind as the CBR shell. It is useful to compare the results of the current study with the results of those two studies. Of particular interest are the predictive accuracies obtained and the sample sizes used in those studies. Buta (1994) develops a CBR that predicts corporate bond ratings. Using a sample of 
1,039 firms from Compustat and financial ratios derived therefrom, Buta (1994) reports an overall classification accuracy of $\mathbf{9 0 . 4 \%}$. However, careful examination of Buta (1994) shows that only bond rating categories with more than 250 cases provide such high accuracy. Two other bond rating categories, $\mathrm{CC}$ and $\mathrm{C}$, have only four and eight cases respectively, and ReMind could not classify these cases at all. Additional evidence of sample size limitations is provided by Van Zeeland (1993), who uses ReMind to build a case library consisting of 244 firms that underwent an IRS audit. The firms are classified into one of four types of audit categories and a decision tree is built for the purpose of predicting what type of audit a hypothetical firm is likely to undergo. Van Zeeland (1993) tests the decision tree by classifying 27 new cases into one of four IRS audit categories. Van Zeeland (1993) reports accuracy rates of $25 \%(\mathrm{n}=4), 0 \%(\mathrm{n}=2), 14.29 \%(\mathrm{n}=7)$, and $57.14 \%$ $(n=14)$ for the four audit categories. From examination of Van Zeeland's (1993) results, it appears that predictive accuracy is highly influenced by sample size. These two studies provide evidence that the small sample size for bankrupt firms (relative to the sample size for nonbankrupt firms) may be driving the results obtained in the current study, and may provide one reason why the nonbankrupt firms are classified so much more successfully. Also, given the small sample size of bankrupt firms, data for the bankrupt firms is thinner. Given the clustering algorithm's process of chopping the sample down into smaller pieces in searching recursively for the variable that minimizes the variance in predicting bankruptcy, CBR may fail because of the thinness of data. Logit, on the other hand, does not 
chop the sample down into smaller pieces, but rather considers only two classification possibilities for a given firm: bankrupt or not bankrupt. Thus, the clustering algorithm in ReMind may not accommodate smaller sample sizes.

Although the specific purpose of this research is not to examine the stability of Ohlson's (1980) logit model over time, some interesting observations can be drawn from inspection of the logit results. Based on Begley, Ming, and Watts (1995), a priori expectations are that the re-estimated logit model will perform worse than Ohlson's (1980) original model. This expectation is realized. Neither model one nor model two attain the predictive accuracy of Ohlson's (1980) original model, which reports an average error rate of .149 for model one, and .144 for model two. ${ }^{45}$ In comparing the performance of the current study's logit models with the performance of those of Begley, Ming, and Watts (1995), Begley, Ming, and Watts (1995) attain a lower overall error rate for model one (.18), while the current study attains an overall error rates of .225 for model one. This outcome may be due to sample-specific factors or to the fact that they have more observations which may yield better estimators. Begley, Ming, and Watts (1995) use data from the 1980s, while the current study incorporates data from the late 1970 s also. Perhaps factors unique to data from the 1970 s influence the logit results. A replication of the study would provide additional evidence of the true error rates using Ohlson's (1980) logit model.

${ }^{45}$ Ohlson (1980) does not report type I and type II errors for model three. 
Also based on Begley, Ming, and Watts (1995), the out-of-period test sample is expected to have a lower predictive accuracy than the in-period test sample. For example, Begley, Ming, and Watts (1995) find that in testing Ohlson's (1980) original logit model with data from the 1980s, the overall error rate rises from .14 to .18 for model one. Again, examination of Table 27 reveals that while this expectation is true for models two and three, model one for the out-of-period test sample actually performs slightly better than the in-period test sample for model one. This result could also be driven by sample-specific factors. Compared with the Begley, Ming, and Watts (1995) findings, the logit models generated and tested with an out-of-period sample have comparable predictive accuracy, with models one and two attaining overall error rates of .18 and .32 .

Based on the findings of this study, CBR is not useful in predicting bankruptcy. However, this conclusion is based only on the current study and this study's limitations. Future studies would negate or confirm the findings of this study. Ohlson's (1980) logit model of bankruptcy prediction, on the other hand, is useful for predicting bankruptcy, and appears to be relatively stable over time.

\section{Limitations}

Following Ohison (1980), the current study is limited to manufacturing and industrial firms (SIC codes less than 4000 and between 5000 and 5999). This focus excludes industries such as utilities, banks, insurance companies, and REITs. Such exclusion is important because financial ratios are not comparable across industries. For example, a bank's leverage ratio is generally around six or seven, while a 
manufacturing firm's leverage ratio is generally around two. Therefore, to combine banks and manufacturing firms in one sample would be a serious design flaw. This criterion also promotes a more homogeneous sample and enhances comparability of the CBR models and Ohlson's (1980) logit models. The results here may not be valid in other industries.

As discussed previously, the sample size for the bankrupt firms is small. There are several reasons why the sample of bankrupt firms is small. First, bankruptcy is a rare event in the population of large publicly traded firms. Only about four percent of these firms on average go bankrupt. Second, the sample selection criterion of manufacturing and retailing firms limits the sample. Also, the Compustat tapes subscribed by Louisiana State University do not include NASDAQ firms, and thus the current study does not include NASDAQ firms. Begley, Ming, and Watts (1995) obtain a final sample of 165 bankrupt firms from 1980-1989. These researchers have access to the full Compustat tapes, including NASDAQ files, which provides a substantially larger sample size of bankrupt firms might have been available. Even so, as indicated in the previous discussion, the clustering algorithm in ReMind may well require a thousand bankrupt cases or more to function as it is intended to function. A possible solution to the dilemma of sample size for bankrupt firms is discussed in the "Suggestions for Future Research" section of this chapter.

An artifact of bankruptcy studies is that the variables are not selected based on an economic theory of bankruptcy. Rather, the variables are chosen for their 
appearance in the literature. Absent a theory of bankruptcy, one is left to rely on the literature for guidance as to which variables have proven to be useful in predicting bankruptcy. A different set of variables would provide a different decision tree and possibly different predictive accuracy results.

A further limitation to $\mathrm{CBR}$ is that there is no one set of explanatory variables provided as output from the process as there is in traditional statistical methods. The hierarchical ranking of variables may be observed for a given decision tree, but this ranking often changes dramatically for another test sample. Thus, the decision trees must be averaged in order to give a predictive accuracy.

Another limitation in the current study is that the reason for filing bankruptcy is not considered. Some firms in the 1980's filed bankruptcy for strategic reasons such as to avoid a hostile takeover attempt or to break a union. These firms are not financially distressed and their inclusion in the current study might tend to distort the results somewhat if a large number of such firms were included.

In considering the experimental design issue of validity, researchers are aware of the trade-off between internal and external validity. That is, a study that has high internal validity due to strong control will have very little external validity, and the results will usually not be generalizable beyond that study. Conversely, a study high in external validity and therefore very generalizable will have very little internal validity. The lack of internal validity means the study cannot establish causation between the dependent and independent variables, but only an 
association. The current study, being an archival research project, has very little internal validity since there is no control of the independent variables. Therefore, only an association between the independent variables and the cuependent variable (bankrupt or not bankrupt) is asserted. There is a higher degree of external validity since the current results can be generalized to other firms within the sample selection criterion of publicly traded manufacturing and industrial firms. However, the results cannot be generalized to other industries or to small firms. This study's design also does not consider interactions between independent variables. A future study may consider this issue.

Finally, this study uses one commercial CBR shell, ReMind, to serve as the inference engine for the CBR. Although ReMind is the best known and most reputable CBR shell, there are other shells, including Esteem (Esteem Software, Inc., Cambridge City, Indiana) and CBR Express (Inference Corp., El Segundo, California). Replication of this study using another CBR shell would provide evidence as to the validity of ReMind's clustering algorithm versus another shell's algorithm.

\section{Suggestions for Future Research}

Research in the area of CBR and accounting appears to be limited (assuming a researcher wishes to use ReMind) if indeed thousands of cases are needed by ReMind's clustering algorithm to function properly. O'Leary (1993) suggests use of generic algorithms to simulate data, and accounting researchers may be interested in simulating data for a bankruptcy study to determine the predictive 
accuracy of such a CBR. Such simulated data should include a thousand cases or more to ensure a reliable result, following the advice of Sonquist, Baker, and Morgan (1971). The current study could provide a basis for generating simulated data for such a project. The characteristics of individual variables could be observed (i.e., mean, median, kurtosis), and this information then used in SAS to generate data with the same characteristics. This approach ensures that the resultant case library is comparable with the current study, only on a much larger scale. A CBR model could then be constructed and tested in order to resolve the questions of sample size and predictive accuracy.

Other applications of CBR may prove more useful than a bankruptcy study. Auditing, in particular, may have some interesting implications for CBR. Areas such as fraud detection may be fruitful domains for application of CBR. Such a study might develop a CBR model that could identify the presence or absence of managerial or employee fraud based on a set of indicator red flags. Again, data availability is a consideration, depending upon the results of the simulation study. Other CBR shells might be explored, either in the context of bankruptcy prediction or another application. Some success has been achieved using CBR programs written from scratch. For example, Morris (1994), Denna et al. (1992), and Mukhopadhyay, Vicinanza, and Prietula (1992) all wrote original CBR programs as opposed to using a CBR shell. Perhaps these programs are needed to adjust the clustering algorithms for small sample sizes found in some accounting research studies. Future research is needed to make this determination. 
Finally, the almost universal criticism of bankruptcy modeling studies is that the resulting models are not based on an economic theory of bankruptcy. Development of an economic theory of bankruptcy would enable researchers to $a$ priori establish better predictors. Such predictors could then be used to generate more accurate models of bankruptcy prediction. 


\section{REFERENCES}

Adrion, W., M. Branstad, and J. Cherniavsky. 1982. Validation, verification, and testing of computer software. ACM Computing Surveys 14(2): 159-192.

Altman, E. 1968. Financial ratios, discriminant analysis and the prediction of corporate bankruptcy. Journal of Finance (September): 589-609.

- 1983. Corporate financial distress. New York: John Wiley \& Sons.

Altman, E., R. Avery, R. Eisenbeis, and J. Sinkey. 1981. Application of classification techniques in business, banking and finance. Greenwich, CT: JAI Press.

Altman, E., R. Haldeman, and P. Narayanan. 1977. Zeta analysis. Journal of Banking \& Finance (June): 29-54.

Ashley, K. 1987. Modeling Legal Argument: Reasoning with cases and hypotheticals. $\mathrm{PhD}$ dissertation, University of Massachusetts.

. 1991. Reasoning with cases and hypotheticals in HYPO. International Journal of Man-Machine Studies, 34: 753-96.

Ashley, K. and Rissland, E. 1988. A case-based approach to modeling legal expertise. IEEE Expert (Fall), 3: 70-77.

Bain, W. M. 1986a. JUDGE: A case-based reasoning system. Machine Leaming: A Guide to Current Research. Boston: Kluwer Academic Publishers.

Bain, W. M. 1986b. Case-based reasoning: A computer model of subjective assessment. $\mathrm{PhD}$ dissertation, Yale University.

Baldwin, J. and G. W. Glezen. 1992. Bankruptcy prediction using quarterly financial statement data. Journal of Accounting, Auditing \& Finance: 269-2.

Barletta, R. 1991. An introduction to case-based reasoning. AI Expert (August): $42-49$. 
Bareiss, E. R. 1989. Exemplar-based knowledge acquisition: $A$ unified approach to concept representation, classification, and learning. Boston: Academic Press.

Bareiss, E. E., B. Porter, and C. Weir. 1988. Protos: An exemplar-based learning apprentice. International Journal of Man-Machine Studies 29: 549-561.

Beaver, W. 1966. Financial ratios as predictors of failure. Journal of Accounting Research (Selected Studies): 71-111.

1968. Alternative accounting measures and predictors of failure. Accounting Review (January): 113-22.

Begley, J., J. Ming, and S. Watts. 1995. Bankruptcy classification errors in the 1980s: An empirical analysis of Altman and Ohlson's models. Working paper, University of British Columbia.

Biggs, S. F., W. Messier, Jr., and J. Hansen. 1987. An investigation of auditor decision processes in the evaluation of internal controls and auditor scope decisions. Journal of Accounting Research (Spring) 21: 234-255.

Blum, M. 1974. Failing company discriminant analysis. Journal of Accounting Research (Spring): 1-25.

Boritz, J. E. and D. B. Kennedy. 1995. Effectiveness of neural network types for prediction of business failure. Expert Systems with Applications, 9:4, forthcoming.

Boritz, J. E., D. B. Kennedy, and A. M. Albuquerque. 1994. Predicting corporate failure using a neural network approach. Intelligent Systems in Accounting, Finance and Management, 2: 1-18.

Branting, L. 1989. Integrating generalizations with exemplar-based reasoning. In Case-based reasoning: Proceedings of a workshop on case-based reasoning. Pensacola Beach, FL: 224-9.

Breiman, L., J. Friedman, R. Olshen, and C. Stone. 1984. Classification and Regression Trees. Belmont, CA: The Wadsworth Statistics/Probability Series.

Brown, C. E. and U. Gupta. 1994. Applying case-based reasoning to the accounting domain. Intelligent Systems in Accounting, Finance and Management 3: 205-221.

Business Failure Record USA. 1982. New York: The Dun \& Bradstreet Corporation. 
Buta, P. 1994. Mining for financial knowledge with CBR. AI Expert (February): 34-40.

Casey, C. and N. Bartczak. 1984. Cash flow-- It's not the bottom line. Harvard Business Review (July-August): 61-66.

Chen, K. H. and T. A. Shimerda. 1981. An empirical analysis of useful financial ratios. Financial Management (Spring): 51-60.

Coakley, Gammill, and Brown. 1995. Working paper, University of Oregon. Artificial neural networks in accounting and finance.

Cognitive Systems, Inc. 1992. Functional Specifications for the ReMind Development System, version 1.1. Stamford, CT.

Collins, R., and R. Green. 1982. Statistical methods for bankruptcy prediction. Journal of Economics and Business 34: 349-54.

Dambolena, I., and S. Khoury. 1980. Ratio stability and corporate failure. Journal of Finance (September): 1017-26.

Deakin, E. 1972. A discriminant analysis of predictors of business failure. Journal of Accounting Research (Spring): 167-79.

Denna, E. 1989. Auditor memory and determining the likelihood of material error: a computational model. PhD dissertation, Michigan State University.

Denna, E., J. Hansen, R. Meservy, and L. Wood. 1992. Case-based reasoning and risk assessment in audit judgment. Intelligent Systems in Accounting, Finance, and Management 1: 163-171.

Dowdy, S. and S. Wearden. 1991. Statistics for Research. New York: John Wiley \& Sons.

Doyle, P. 1972. The use of automatic interaction detector and similar search procedures. Operational Research Quarterly 24: 465-469.

Frydman, H., E. Altman and D. Kao. 1985. Introducing recursive partitioning for financial classification: The case of financial distress. Journal of Finance (March): 269-91.

Gentry, J., P. Newbold, and D. Whitford. 1985. Classifying bankrupt firms with funds flow components. Journal of Accounting Research (Spring): 146-59. 
Gombola, M., and J. Ketz. 1983. Note on cash flow and classification patterns of financial ratios. VTheAccounting Review (January): 105-114.

Goodman, M. 1989. CBR in battle planning. In Case-based reasoning: proceedings of a workshop on case-based reasoning. Pensacola Beach, FL.

Hamer, M. 1983. Failure prediction: Sensitivity of classification accuracy to aiternative statistical methods and variable sets. Journal of Accounting and Public Policy 2: 289-307.

Hansen, J., R. Meservy, and L. Wood. 1995. Case-based reasoning: application techniques for decision support. Intelligent Systems in Accounting, Finance, and Management 4: 137-146.

Hansen, J. V., Merservy, R. D., Wood, L. E. and Denna, E. L. 1991. Case-based reasoning and assessing the likelihood of auditor litigation. Presented at the Fourth International Symposium on Expert Systems in Accounting, Finance and Management, Pasadena, CA.

Hartigan, J. 1975. Clustering Algorithms. New York: John Wiley \& Sons.

Heald, G. 1972. The application of the automatic interation detector (A.I.D.) programme and multiple regression techniques to the assessment of store performance and site selection. Operational Research Quarterly 23: 445-457.

Huang, W. 1990. A trademark infringement case retrieval and reasoning system. $\mathrm{PhD}$ dissertation, Washington State University.

Jones, F. 1987. Current techniques in bankruptcy prediction. Joumal of Accounting Literature 6: 131-164.

Kolodner, J. L. 1993. Case-Based Reasoning. San Mateo, CA: Morgan Kaufmann.

Kolodner, J. L. and R. L. Simpson. 1989. The MEDIATOR: Analysis of an early case-based problem solver. Cognitive Science 13: 507-49.

McFadden, D. 1973. Conditional logit analysis of qualitative choice behavior. In Frontiers in Econometrics, edited by P. Zarembka. New York: Academic Press.

Mensah, Y. 1983. The differential bankruptcy predictive ability of specific price level adjustments: Some empirical evidence. The Accounting Review (April): 228-46. 
Meservy, R. D., A. D. Bailey, Jr. and P. E. Johnson. 1986. Internal control evaluation: A computational model of the review process. Auditing: $A$ Journal of Practice \& Theory 6: 44-74.

Morgan, J. and J. Sonquist. 1963. Problems in the analysis of survey data, and a proposal. American Statistical Association Journal (June): 415-434.

Morris, B. W. 1992. Case-based reasoning in internal auditor evaluations of EDP controls, PhD dissertation, University of Pittsburgh.

Morris, B. W. 1994. SCAN: A case-based reasoning model for generating information system control recommendations. International Journal of Intelligent Systems in Accounting, Finance and Management 3: 47-63.

Mukhopadhyay, T., S. Vicinanza, and M. Prietula. 1992. Examining the feasibility of a case-based reasoning model for software effort estimation. MIS Quarterly (June): 155-171.

Norton, C., and R. Smith. 1979. A comparison of general price-level and historical cost financial statements in the prediction of bankruptcy. The Accounting Review (January): 72-87.

Ohlson, J. 1980. Financial ratios and the probabilistic prediction of bankruptcy. Journal of Accounting Research (Spring): 109-31.

O'Leary, D. E. 1993. Verification and validation of case-based systems. Expert Systems with Applications 6: 57-66.

Rissland, E. L. and D. Skalak. 1991. CABARET: Rule interpretation in a hybrid architecture. International Journal of Man-Machine Studies 34: 839-887.

Schank, R.C. 1982. Dynamic memory: $A$ theory of reminding and learning in computers and people. New York: Cambridge University Press.

Selfridge, M. and Cuthill, B. 1989. Retrieving relevant out-of-context cases: A dynamic memory approach to case based reasoning. In Proceedings of a workshop on case-based reasoning (DARPA): 313-17. Pensacola Beach, FL.

Sonquist, J., E. Baker, and J. Morgan. 1971. Searching for structure. Ann Arbor, MI: Institute of Social Research, The University of Michigan.

Stottler, R. H. 1994. CBR for cost and sales prediction. AI Expert (August): 2533. 
Summers, E. L. 1991. Accounting Information Systems, Second Ed. Boston: Houghton Mifflin Company.

Sycara, K. P. 1988. Using case-based reasoning for plan adaptation and repair. In Kolodner, J. L. (ed.), Proceedings of the workshop on case-based reasoning (DARPA), Clearwater Beach, FL 10-13 May 199. San Mateo, CA: Morgan Kaufmann.

Sycara, K. P. 1990. Negotiation planning: An AI approach. European Journal of Operational Research 46:216-34.

Van Zeeland, W. J. 1993. Database mining in company tax returns. Working paper, Vlaardingen, the Netherlands.

Weiss, S. M. and I. Kapouleas. 1989. An empirical comparison of pattern recognition, neural nets, and machine learning classification methods. In Proceedings of the 11th IJCAI.

Wilcox, J. 1971. A simple theory of financial ratios as predictors of failure. Journal of Accounting Research (Autumn): 389-95.

Zahedi, F. 1993. Intelligent Systems for Business. Boston: Wadsworth, Inc.

Zavgren, C. 1983. The prediction of corporate failure: The state of the art. Journal of Accounting Literature 2: 1-37. 


\section{VITA}

Stephanie M. Bryant is an assistant professor of accounting at James Madison University and a certified public accountant. She attended Louisiana State University from 1985 - 1988 and 1993 - 1996, where she earned her bachelor of science degree in accounting in December, 1988 and expects to receive her doctor of philosophy degree in accounting in December, 1996. While a graduate teaching assistant at Louisiana State University, Stephanie earned many awards, including the Lloyd F. Morrison accounting department award for outstanding teaching in 1995 and 1996 and the 1996 Alumni Association award for outstanding teaching by a doctoral student. Stephanie worked for the Louisiana Association of Educators as Director of Accounting from 1991 - 1993 and for KPMG Peat Marwick as a tax specialist from 1989 - 1991. She is married and has two children. 
Candidate: Stephanie M. Bryant

Hajor Field: Accounting

Title of Dissertation: A Case-Based Reasoning Approach to Bankruptcy Prediction Modeling

\section{Approved:}

Bubara lostolow

Major Profesadr and chairman

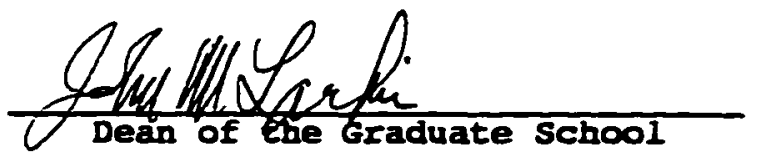

EXAMINING COMMITTEE:
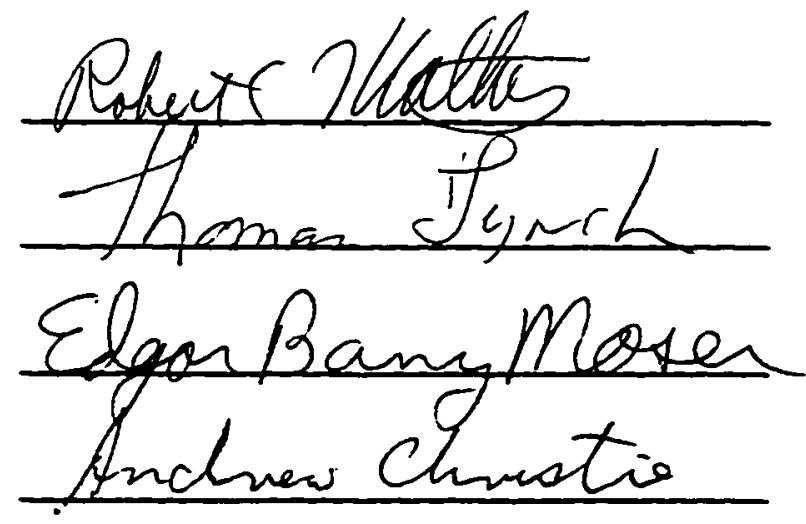

Date of Bxamination:

October 25, 1996 